\title{
Using Organic Synthesis and Chemical Analysis to Understand the Photochemistry of Spore Photoproduct and Other Pyrimidine Dimers
}

\author{
Lei Lia,b (D) \\ a Department of Chemistry \& Chemical Biology, \\ Indiana University-Purdue University Indianapolis \\ (IUPUI), 402 N. Blackford Street, LD 326, 46202 \\ Indianapolis, USA \\ ${ }^{b}$ Department of Dermatology, Indiana University \\ School of Medicine, 46202 Indianapolis, USA \\ lilei@iupui.edu
}

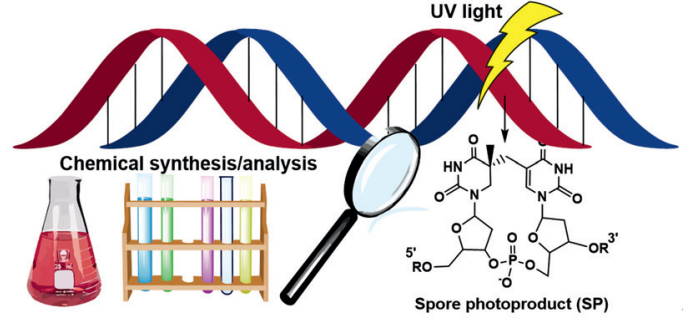

\section{Introduction}

Accepted after revision: 06.09.2017

Published online: 30.11 .2017

DOI: 10.1055/s-0036-1590981; Art ID: st-2017-a0416-a

Abstract Pyrimidine dimerization is the dominant DNA photoreaction occurring in vitro and in vivo. Three types of dimers, cyclobutane pyrimidine dimers (CPDs), pyrimidine (6-4) pyrimidone photoproducts (6$4 \mathrm{PPs}$ ), and the spore photoproduct (SP), are formed from the direct dimerization process; it is of significance to understand the photochemistry and photobiology of these dimers. Traditionally, pyrimidine dimerization was studied by using the natural pyrimidine residues thymine and cytosine, which share similar chemical structures and similar reactivity, making it sometimes less straightforward for one to identify the key pyrimidine residue that needs to be excited to trigger the photoreaction. We thus adopted synthetic chemistry to selectively modify the pyrimidine residues or to introduce pyrimidine analogs to the selected positions before UV irradiation is applied. By monitoring the subsequent outcomes from the photoreaction, we were able to gain unique mechanistic insights into the photochemistry of SP as well as of CPDs and 6-4PPs. Moreover, our approaches have resulted in several useful "tools" that can facilitate the understanding of lesion photobiology. Our results summarized in this account illustrate what organic synthesis/chemical analysis may allow us to achieve in future DNA lesion biology studies.

1 Introduction

2 Using the Deuterium Labeling Strategy to Understand SP Formation

3 Using Microcrystals to Reveal the Reaction Intermediates in SP Formation

4 Using a Phosphate Isostere to Understand the SP Structure

5 Synthesis of SP Phosphoramidite and SP Structural Studies

6 Using a Thymine Isostere to Understand CPD Formation

7 Using a Thymine Isostere to Understand 6-4PP Photoreaction

8 Understanding the Chemical Stability of SP

9 Understanding the Chemical Stability of 6-4PP

10 Summary and Perspectives for Future Research

Key words chemical synthesis, pyrimidine dimers, spore photoproduct, cyclobutane pyrimidine dimers, pyrimidine (6-4) pyrimidone, photoproduct, photoreaction
DNA photolesions induced by the UV portion of solar irradiation are the dominant cause for the occurrence of skin cancer. ${ }^{1}$ The UV region of the solar light can be divided into three sub-regions according to the wavelength, UVC (215$280 \mathrm{~nm})$, UVB (280-315 nm), and UVA (315-400 nm). Fortunately, the high-energy portion of the UV irradiation, that is all UVC light and approximately 95\% of the UVB light, is filtered out by the ozone layer. Only a small portion of the UVB light and all UVA light reach the earth surface. Once absorbed, UVB and UVA may excite nucleobases in the genomic DNA, which subsequently react to form various DNA photolesions. The UVB photons may promote the direct formation of DNA lesions due to the high energy; whether UVA light is strong enough to directly induce DNA lesions is still under debate. ${ }^{2}$ On the other hand, UVA light can prowhich then reacts with DNA producing DNA damages. Moreover, although absent in natural solar light, the shortwavelength UVC light also directly leads to DNA photolesions and is widely used in food and water sterilization processes.

Although all four nucleobases can undergo a photoreaction upon UV excitation, the pyrimidine residues are much more reactive than the purine residues. ${ }^{3-5}$ The most common pyrimidine photoreaction is the dimerization that leads to three major types of products: cyclobutane pyrimidine dimers (CPDs), pyrimidine (6-4) pyrimidone photoproducts (6-4PPs), and 5-thyminyl-5,6-dihydrothymine [i.e. the spore photoproduct (SP)] (Figure 1). Dimerization between a pyrimidine and a purine as well as between two purine residues may also occur but much less frequently. ${ }^{6}$ Additionally, both the purine and pyrimidine residues are duce reactive oxygen species (ROS) such as singlet $\mathrm{O}_{2}$, 
<smiles>CC1(C)C(=O)NC(=O)N(C2CC([Pb])C(COP(=O)([O-])OC3CC(O)C(COP)O3)O2)C1C1CC(O)C(=O)NC1=O</smiles>

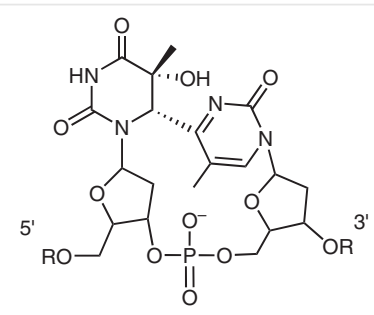

CPD<smiles>Cc1cn(C2CN(C3CC(OP(=O)([O-])OC4CC(O)C(CO)O4)C(=O)NC3=O)CC(C)(C)O2)c(=O)[nH]c1=O</smiles>

SP

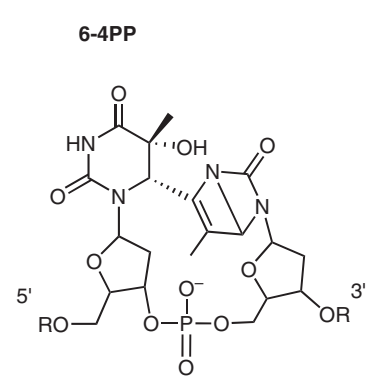

Dewar PP

Figure 1 The chemical structures of the three major types of dimers formed between two thymine residues, CPD, 6-4PP, and SP. Replacement of one or both of the thymine residues by cytosine in the dipyrimidine step results in the corresponding CPD and 6-4PP species with structures similar to those of the thymine dimers shown. SP is only known to be formed between two thymine residues. Moreover, 6-4PP can absorb UVA/UVB light giving rise to the Dewar valence photoproduct (Dewar PP).

subjected to oxidative modifications due to their electronrich nature. ${ }^{6}$

Among the three pyrimidine dimers, CPDs are the most abundant photoproducts in UV-irradiated isolated DNA and cellular DNA in normal vegetative cells. The CPD formation occurs through a $[2+2]$ photoaddition mechanism that can occur between any combination of $\mathrm{T}$ and $\mathrm{C}$. Among them, the TT step is the most favorable site followed by TC,CT, and CC. ${ }^{7}$ CPD formation under UVC and UVB light is reversible. ${ }^{8}$ Because pyrimidine residues absorb at around $260 \mathrm{~nm}$ and CPDs possess some absorption peaks around $230 \mathrm{~nm}$, the equilibrium between CPDs and undamaged dipyrimidine

sequences is controlled by the UV wavelength. When UVB light is applied, more than $90 \%$ of TT dinucleotide can be converted into CPD. ${ }^{9}$ Although the pyrimidine residues barely absorb in the UVA region, UVA light does promote CPD formation. ${ }^{10}$ Latest results suggest that the interbase charge-transfer states in oligonucleotides populated by absorption of UVA photons may be converted to the $\pi-\pi^{*}$ Frenkel excitons that give rise to CPDs. ${ }^{11}$ Interestingly, CPDs may also form several hours after UVA irradiation. ${ }^{12}$ These "dark" CPDs were indicated to be mediated by some chemical excitation processes instead of direct photoexcitation. ${ }^{12}$

In addition to CPDs, 6-4PPs are another type of relatively abundant pyrimidine dimers found in isolated and cellular DNA after UV irradiation. 6-4PPs are suggested to occur via an oxetane or azetidine intermediate formed between the involved pyrimidine residues after photoexcitation; the intermediate then thermally decomposes to the corresponding 6-4PP. ${ }^{3}$ UVC light favors 6-4PP photochemistry. The 6-4PP yield is much lower under UVB light, whereas UVA light cannot induce 6-4PP formation. ${ }^{4}$ Among dipyrimidine sequences, TC favors 6-4PP formation most, followed by TT and CC. The CT sequence is the least likely to promote the 6-4PP photochemistry. ${ }^{7}$ Such a trend is very different from that observed from the CPD photochemistry. Since it is now known that CPD formation involves the Frenkel excitons, while 6-4PP photochemistry is mainly controlled by the charge-transfer states, ${ }^{11}$ the different reaction pattern exhibited by various bipyrimidine sequences may simply reflect the different reaction mechanism behind. Moreover, 6-4PP absorbs UVA/UVB light and isomerizes to the Dewar Valence photoproduct (Dewar PP, Figure 1). ${ }^{13}$ Under solar light, about $20 \%$ of the $6-4$ PPs were converted to Dewar PPs in marine microorganisms, ${ }^{14}$ indicating that Dewar PP in genomic DNA may be highly biologically relevant.

Different from CPDs and 6-4PPs, SP was discovered in UV-irradiated bacterial endospores as the solely dominant DNA photolesion. ${ }^{15}$ Under strong UV irradiation, as much as $28 \%$ of the total thymine residues in the spore genomic DNA can be converted to SPs. ${ }^{16}$ Since spores are dormant cells, the formed SPs simply accumulate until spores start germi-

\section{Biographical sketch}

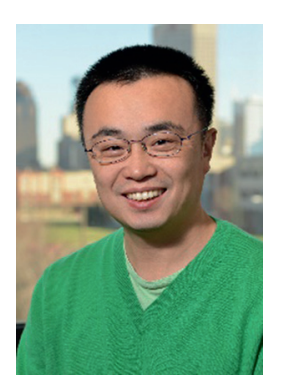

Lei Li received his B.S. and M.S. from Peking University at Beijing, China and his Ph.D. from the Johns Hopkins University in 2005 under the guidance of Professor Kenneth D. Karlin. He carried out his postdoctoral research with Professor Neil Marsh at the University of Michigan before starting his independent research position as an assistant
Professor of Chemistry and Chemical Biology at Indiana University Purdue University Indianapolis (IUPUI) in 2009. He was promoted to an associate Professor with tenure in 2015 and also holds an adjunct appointment in Department of Dermatology, Indiana University School of Medicine. His research mainly focuses on the mecha- nistic elucidation of the formation and enzymatic repair of various thymine dimers including the spore photoproduct. The honors and awards he received include NIH Pathway to Independence Award (2008), NSF CAREER Award (2015), and American Cancer Society Research Scholar Award (2016). 
nation. By then, a spore-unique enzyme named spore photoproduct lyase (SPL) quickly converts SPs back to TT residues through a radical-mediated direct reversal mechanism. ${ }^{17}$ The almost exclusive formation of SP in UVirradiated spores and the efficient SP repair in germinating and outgrowing spores are mainly responsible for spores' extremely high UV resistance, ${ }^{18-21}$ which can be 100 -fold higher than that of the corresponding vegetative cells as shown by some Bacillus spores. ${ }^{22}$

All three types of pyrimidine dimers were discovered in the 1960 s. $^{8,15,23}$ After extensive research in the past half century, a great deal has been revealed on the photochemistry and photobiology of CPDs and 6-4PPs. In contrast, the knowledge of SP was rather limited, as summarized in the review article by Desnous et al. in $2010 .^{18}$ To better understand the SP photochemistry and photobiology has thus been a major focus of my research group during the past eight years at IUPUI. Our SP research may be divided into two major schemes: to understand the SP formation and to elucidate its repair by SPL.

Together with other research groups, ${ }^{20,24,25}$ we have drastically advanced the mechanistic elucidation of SPL. Our SPL studies have shown that the previous mechanism, ${ }^{25}$ which excludes the involvement of protein residues in the radical transfer process, falls short. SPL harbors a sophisticated radical transfer chain that at least is composed of a cysteine and two tyrosine residues, ${ }^{26}$ making it the first and only enzyme in the large radical SAM superfamily $(>110,000 \text { members })^{27}$ to utilize a protein-harbor radical transfer pathway for catalysis. The integrity of the transfer chain is essential for the enzyme catalysis, as a seemingly harmless glycine mutation that is more than $17 \AA$ away from the enzyme active site can almost completely abolish the enzyme activity. ${ }^{28}$ Moreover, SP in duplex DNA is a surprisingly poor substrate for SPL, indicating that SPL may be assisted by other protein partners to access SP in the genomic DNA to initiate the lesion repair in germinating spores. ${ }^{29}$ Our SPL studies have been extensively reviewed in recent years. ${ }^{17,30}$

In this account, "we would summarize our work using organic synthesis and chemical analysis" means to advance our understanding of SP photochemistry. We have proved that SP is formed through an intramolecular H-atom transfer mechanism. ${ }^{31}$ We solved the first crystal structure of dinucleotide SP, which reveals the impact of SP on the chemical structure of the involved thymine residues. ${ }^{32}$ We prepared a SP TpT phosphoramidite, which for the first time enables SP incorporation into an oligonucleotide with high purity. ${ }^{33}$ Using an SP-containing oligonucleotide, we solved the first structure of the dinucleotide SP in duplex DNA, and found that SP induces only a minor disturbance of the DNA helical structure. ${ }^{34}$ Additionally, using thymine isosteres, we recently extended our studies to the under- standing of the $\mathrm{CPD}^{35,36}$ and 6-4PP photochemistry, ${ }^{37}$ and have gained interesting mechanistic insights into the formation of these two dimers.

\section{Using the Deuterium Labeling Strategy to Understand SP Formation}

Our first SP research project was to elucidate the reaction mechanisms of SP formation. Our rationale is that both SP and TpT have the same number of hydrogen atoms; therefore SP formation may be simply mediated by the rearrangement of hydrogen atoms between the two involved thymine residues. Although the rate of SP formation after thymine photoexcitation has not been studied, it is reasonable to assume that the stacking interaction among neighboring DNA nucleobases will not allow the reaction intermediates to change positions through thermal movement. Consequently, the steric configuration adopted in the TpT step is likely conserved in the resulting SP.

The structure of SP (Figure 1) shows that the C5 position at the 5'-thyminyl residue adopts $R$ configuration as proved by an NMR study. ${ }^{38}$ This agrees with a previous prediction by Kim et al. based on the fact that DNA is a right-handed helix, and therefore only the methyl moiety on the 3'-thymine can be added to the 5'-thymine, leading to the 5R SP stereoisomer in the UV-irradiated spore genomic DNA. ${ }^{39}$ Furthermore, the C6 position at the 5'-thymine of SP has two $\mathrm{H}$ atoms and becomes prochiral. If the extra $\mathrm{H} 6$ atom indeed comes from the 3'-methyl group of another thymine that subsequently becomes the methylene bridge in SP, it should occupy the same side as the methylene bridge. Thus, the transferred $\mathrm{H}$ atom should occupy the $\mathrm{H} 6_{\text {pros }}$ position.

\subsection{SP Formation in the Dinucleotide TpT Photo- reaction}

To test the hypothesis, it is desirable to use deuteriumlabeled thymine residues for photoreaction and follow the deuterium migration within these residues during SP formation with NMR spectroscopy. LC-MS spectrometry, typically used in oligonucleotide analysis, can only reveal whether the isotopes are retained in the product. It cannot provide details on the H-migration pattern and is thus unsuitable for the mechanistic studies here. In this vein, it is also not practical to examine the SP mechanism using a long duplex DNA as it is very difficult to trace all proton signals of a large DNA molecule with NMR spectroscopy. Moreover, to prepare enough SP-containing oligonucleotides through DNA photoreaction for NMR studies is also cost prohibitive. Therefore, the dinucleotide TpT becomes an ideal system. Different from CPDs and 6-4PPs that are prepared by UV irradiation of DNA in aqueous solution, SP formation may be achieved by UV irradiation of singlestrand and/or double-strand DNA in the solid state (dry 
film or ice), even though the yield of SP is less than $1 \%$ of the total TT sequences due to fact that only a small portion of TTs in the solid state adopt the reactive conformation. ${ }^{21}$ Previous studies show that irradiation of dinucleotide TpT in the dry film made by lypholization of TpT aqueous solution afforded dinucleotide SP TpT, ${ }^{38}$ proving the feasibility of using dinucleotide TpT as a work model for SP mechanistic studies.
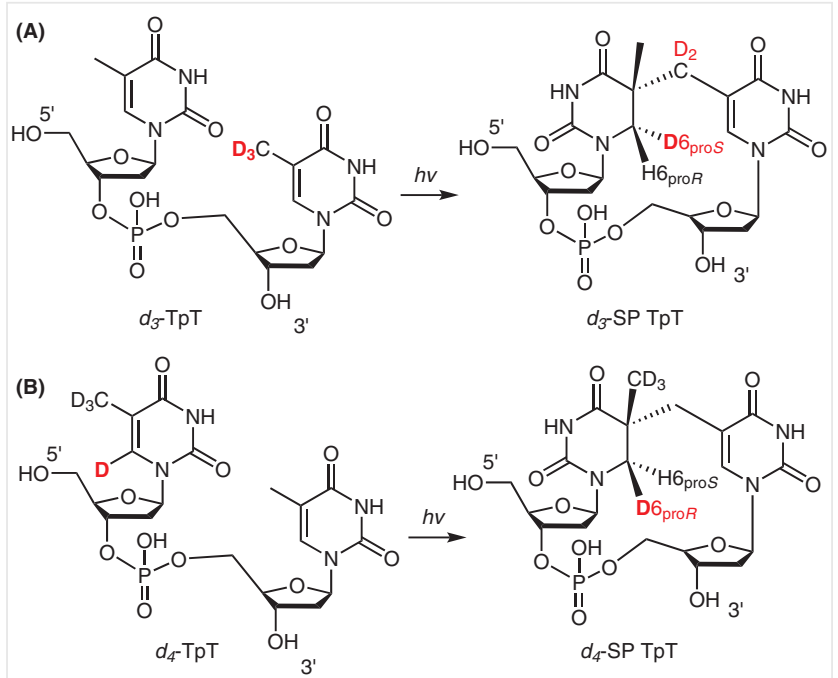

Scheme 1 The projected deuterium migrations in SP formation using selectively labeled dinucleotide TPT

A selectively labeled $d_{3}$-TpT that contains a $d_{3}$-methyl group in the 3'-T (Scheme $1, A$ ) and a $d_{4}$-TpT with all four hydrogen atoms in the 5'-T replaced by deuteriums (Scheme 1, B) were therefore prepared. These labeled TpTs were dissolved in methanol; solvent evaporation yielded nice TpT films. ${ }^{40} \mathrm{UV}$ irradiation of the film produces the corresponding SPs in about 0.1 and $0.4 \%$ yield. ${ }^{31}$ That the SP yield from the $d_{3}$-TpT reaction is lower is likely due to the primary deuterum isotope effect caused by the 3 ' $-\mathrm{CD}_{3}$ moiety as explained in the mechanism in Scheme 3 below. After multiple reactions, the resulting labeled SP TpTs were collected and their structures characterized by NMR spectroscopy. To facilitate structural comparison, nonlabeled SP TpT was prepared through organic synthesis following a procedure modified from the original approach adopted by Kim et al. ${ }^{39}$

The unlabeled SP TpT exhibits two doublets at 3.15 and $3.02 \mathrm{ppm}$ in the ${ }^{1} \mathrm{H}$ NMR spectrum (Figure 2 ), which have been assigned to the $\mathrm{H} 6_{\mathrm{pros}}$ and $\mathrm{H} 6_{\mathrm{proR}}$, respectively, in the previous studies. ${ }^{38}$ In the resulting labeled SP TpTs, the doublets become a singlet as the $\mathrm{H} \rightarrow \mathrm{D}$ replacement eliminates the $\mathrm{H}-\mathrm{H}$ coupling at the $\mathrm{C} 6$ position. Furthermore, the $d_{3}-\mathrm{SP}$ TpT has a singlet signal at $3.14 \mathrm{ppm}$ but no signal at about $3.02 \mathrm{ppm}$, consistent with $\mathrm{H}_{\text {pros }}$ being occupied by a deuterium. The $d_{4}$-SP TPT shows an opposite trend, that is a sin-

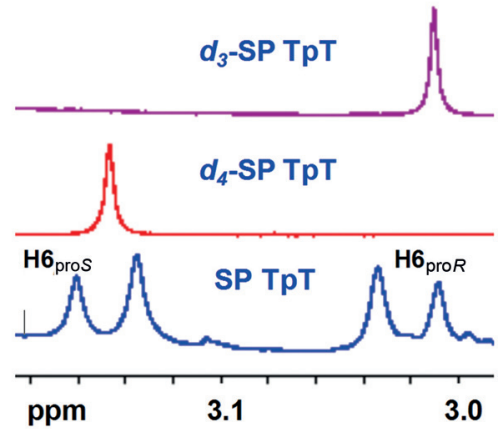

Figure 2 Zoom-in view of ${ }^{1} \mathrm{H}$ NMR signals for the $\mathrm{H}_{\text {pros }}$ and $\mathrm{H} 6_{\text {proR }}$ protons in dinucleotides $d_{3}$-SP TPT, $d_{4}$-SP TpT, and unlabeled SP TPT. The unlabeled SP exhibits two doublets at 3.15 and $3.02 \mathrm{ppm}$ for the two $\mathrm{H} 6$ protons, which are assigned to the $\mathrm{H} 6_{\text {pros }}$ and $\mathrm{H} 6_{\text {proR }}$, respectively. The doublets become a singlet in the two deuterated SP species due to the loss of the $\mathrm{H}-\mathrm{H}$ coupling. Moreover, the $\mathrm{H}_{\text {pros }}$ and $\mathrm{H}_{\text {proR }}$ signals disappear in $d_{3}$-SP TPT and $d_{4}$-SP TpT, respectively, consistent with the reactions predicted in Scheme 1.

glet at $3.01 \mathrm{ppm}$ and no signal at about $3.15 \mathrm{ppm}$, agreeing with $\mathrm{H} 6_{\text {proR }}$ being replaced. Both results agree with the reactions predicted in Scheme 1, supporting the notion that a methyl hydrogen atom is transferred to the $\mathrm{H} 6_{\text {pros }}$ position in the formed SP TpT.

\subsection{SP Formation in Monomeric Thymidine Photo- reactions}

As shown in Figure 2, the deuterium transfer in the dinucleotide SP formation is very clean. It is known that the solid-state monomeric thymidine photoreaction also produces SP. Different from single-strand oligonucleotides, the monomeric thymidine residues do not possess the righthanded stacking charity. As a consequence, the thymidine photoreaction produces a pair of stereoisomers, that is the dinucleoside $5 R$ and $5 S$ SP TT. ${ }^{41}$ Previously, Cadet and coworkers employed the $d_{3}$-thymidine containing a $-\mathrm{CD}_{3}$ moiety in a photoreaction in ice and isolated the formed SP possibly as a mixture of the $5 S$ and $5 R$ diastereomers. However, only two thirds of the generated SP possessed a deuterium on the $\mathrm{C} 6$ carbon. ${ }^{3}$ Although these data suggest a hydrogen migration mechanism, the conclusion was undermined by the incomplete deuterium transfer observed.

The chirality difference is not supposed to change the reaction mechanism; both $5 R$ and $5 S$ SP TT formation should largely agree with the observation in the dinucleotide TpT photoreaction. It is thus of interest to investigate why the same deuterium labeling strategy resulted in different conclusions in these two photoreactions. In this vein, we prepared $d_{3}$-thymidine through a reaction between 2 'deoxyuridine and commercially available $d_{3}$-methyliodide (>99.5\% purity)..$^{42}$ The purity of the generated $d_{3}$-thymidine was analyzed by ESI-MS, which shows that about $99.5 \%$ of the thymidine molecules contain three deuterium atoms 
$\left(-\mathrm{CD}_{3}\right), 0.5 \pm 0.05 \%$ contain two $\left(-\mathrm{CD}_{2} \mathrm{H}\right)$, and about $0.04 \%$ contain no deuterium $\left(-\mathrm{CH}_{3}\right)$; the abundance of monodeuterated species $\left(-\mathrm{CDH}_{2}\right)$ is too low to be detected. ${ }^{42}$ Since the $d_{3}$-thymidine is the dominant species, all other thymidine isotopologues in the mixture are likely to react with another $d_{3}$-thymidine molecule, resulting in three SP isotopologues (Scheme 2).

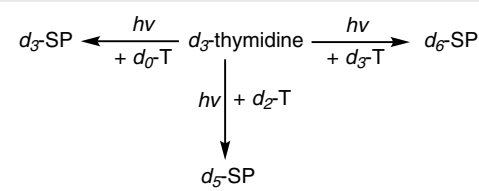

Scheme 2 The projected SP isotopologues after photoreaction using about $99.5 \%$ pure $d_{3}$-thymidine

After photoreaction in ice, the resulting dinucleosides $5 R$ and $5 S$ SP TT were subjected to LC-MS analysis. Surprisingly, although the about $0.5 \% d_{2}$-thymidine is at the baseline level and barely observable without zooming-in in the ESI-MS spectrum, the $d_{5}-5 R$ and $d_{5}-5 S$ SPs formed are clearly observed. ${ }^{42}$ Comparing the signal intensity of $d_{2}$-thymidine with those of $d_{5}$-SPs reveals that $d_{2}$-thymidine is enriched by $16.8 \pm 1.5$-fold for the $5 R$ SP and $10.0 \pm 0.7$-fold for the $5 S$ SP. When the reaction is performed in the dry film made from methanol evaporation, $d_{2}$-thymidine is enriched by 7.5-fold for both the $5 R$ and $5 S$ SP diastereomers.
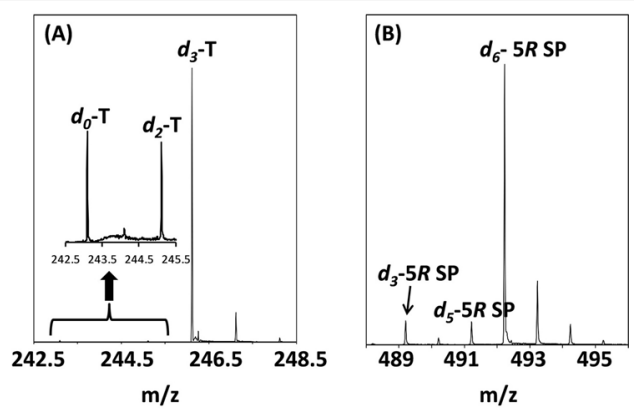

Figure 3 (A) ESI-MS spectrum of the thymidine mixture containing about $99.5 \% d_{3}$-thymidine $\left(d_{3}-T\right)$ and about $0.5 \% d_{2}$-thymidine $\left(d_{2}-T\right)$ that is spiked with unlabeled thymidine $\left(d_{0}-T\right)$ to a final concentration of about $0.5 \%$. The inlet is the zoom-in view of the $0.5 \% d_{0}-T$ and $d_{2}-T$, which are otherwise barely observable. (B) ESI-MS spectrum of the resulting dinucleosides $d_{3^{-}}, d_{5^{-}}$, and $d_{6}-5 R$ SP generated from photoreaction in ice at $-78{ }^{\circ} \mathrm{C}$. The formed $d_{3}$ - and $d_{5}-5 R$ SP are well above the baseline; their yields represent an about 17 -fold enrichment of the corresponding protiated thymidine species.

Similar enrichments were observed in the formed $d_{3}$-SPs. As illustrated in Figure $3, \mathrm{~A}$, the $d_{3}$-thymidine sample that contains about $0.5 \% d_{2}$-thymidine was spiked with the unlabeled $d_{0}$-thymidine to a final concentration of about $0.5 \%$. The resulting mixture was subjected to photoreactions in ice at $-78{ }^{\circ} \mathrm{C}$ and in dry film at ambient temperature. As shown in Figure 3, B, the yield of $d_{3}-5 R$ SP is similar to that of $d_{5}-5 R$ SP, indicating that the less deuterated $d_{0^{-}}$and $d_{2^{-}}$ thymidine species are equally enriched (by about 17 fold) during the SP formation. A similar conclusion was also drawn from the formed $5 S$ SP from the ice reaction and from $5 R$ SP and $5 S$ SP from the dry film reactions. ${ }^{42}$ The $17-$ fold protiated thymidine enrichment during the $5 R$ SP formation suggests that in order to obtain the one third protiated SP observed in the previous studies, only about $2 \%$ of protiated thymidine impurity (combined $d_{0^{-}}, d_{1^{-}}$, and $d_{2^{-}} \mathrm{T}$ ) is needed! Because the previous studies were conducted about 40 years ago, $98 \%$ purity could already be the highest commercially available isotope grade by then.

However, the seemingly small amount of impurity still led to the inconclusive result due to the exceptionally large deuterium discrimination in SP formation. ${ }^{3}$

The SPs produced by these dry film reactions still contain about $6-7 \%$ protiated species; such a low content of impurities would not disturb the mechanistic investigation with NMR spectroscopy. Re-examination of the dinucleosides $5 R$ and $5 S$ SP TT made from the dry film reaction showed that in the $d_{6}-5 R$ SP produced, the $\mathrm{H}_{\text {pros }}$ signal disappears and the $\mathrm{H}_{\mathrm{proR}}$ signal becomes a singlet, consistent with the finding from the TpT photoreaction. For the $d_{6}-5 S$ $\mathrm{SP}$, the $\mathrm{H} 6_{\mathrm{proR}}$ signal disappears, suggesting that the deuterium migrates to the $\mathrm{H} 6_{\mathrm{pro}}$ position. These observations show that the formation of $5 S$ SP mirrors that of the $5 R$ isomer; the $5 R$ and $5 S$ SPs are produced through the same mechanism.

These results provide mechanistic insights into the SP photochemistry. As shown in Scheme 3, UV light first excites the $\mathrm{C} 5=\mathrm{C} 6$ double bond of thymidine to form a diradical. The C6 radical abstracts a hydrogen atom from the methyl group of another thymine, leading to the formation of a 5- $\alpha$-thyminyl and a 5,6-dihydrothymin-5-yl radical. This step is potentially rate-limiting as indicated by the observed primary kinetic isotope effect of 3.5 after deuterium substitution at the 3'-methyl moiety in the dinucleotide TpT photoreaction. ${ }^{31}$ The two radicals then recombine to yield the final product SP.

\section{Using Microcrystals to Reveal the Reaction Intermediates in SP Formation}

The mechanism indicates the presence of two intermediates, a 5- $\alpha$-thyminyl and a 5,6-dihydrothymin-5-yl radical, en route to SP formation (Scheme 3). These radicals were observed previously in X-ray or $\gamma$-ray irradiated thymidine in single crystals or in frozen aqueous solution; 43 although there were no further studies to reveal whether these radicals may recombine to form SP. 


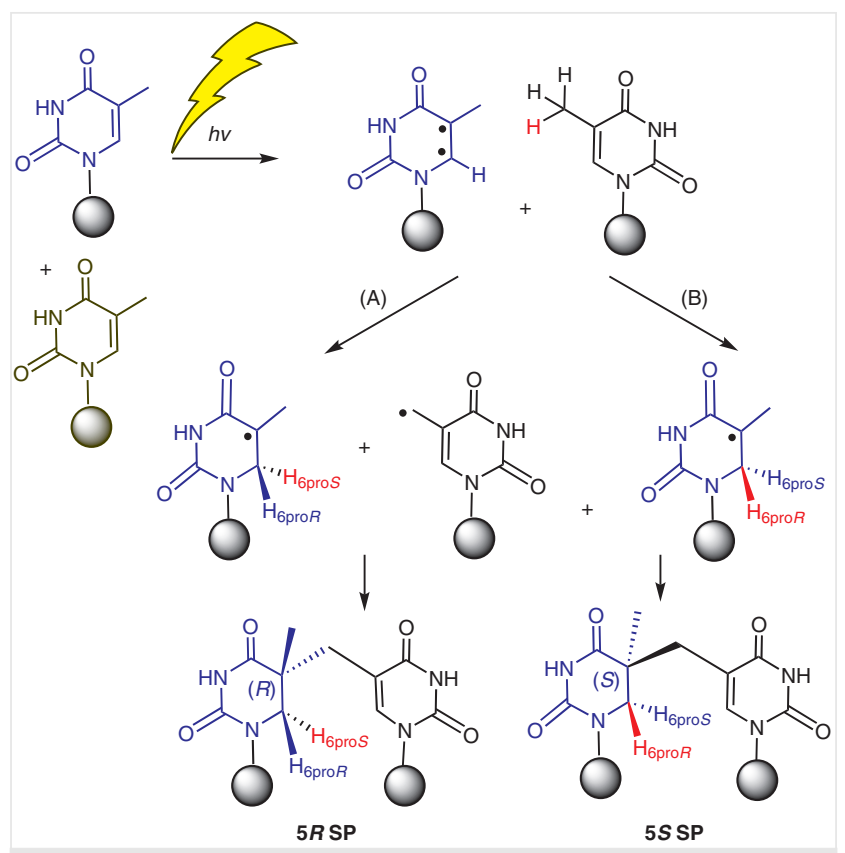

Scheme 3 Proposed reaction mechanism for SP formation. The photoexcitation turns the $\mathrm{C} 5=\mathrm{C} 6$ double bond of thymine into a diradical. The C6 radical abstracts an $\mathrm{H}$ atom from the methyl moiety of another thymine resulting in a methyl radical. Radical recombination then leads to the formation of SP. The reaction pathway (A) represents the stereoconfiguration found in right-handed oligonucleotides; the photoreaction results in the $5 R$ SP. When the reaction is carried out using monomeric thymidine, pathway (B) may occur leading to the formation of the $5 S$ $\mathrm{SP}$ isomer. Clearly, the difference in steric configuration does not change the SP formation mechanism.

\subsection{SP Formation in Thymidine Crystals}

The thymidine crystal structure was solved about 50 years ago. ${ }^{44}$ As shown in Figure 4, the thymidine residues stack on each other in the crystal matrix to form different layers (Figure 4, A). This packing mode places the methyl group of one thymine (a, Figure $4, B$ ) right above the ring of another thymine (b, Figure 4, B). The shortest distance between an $\mathrm{H}$ atom of the $-\mathrm{CH}_{3}$ moiety and the $\mathrm{C} 6$ of the adjacent thymine is only $3.18 \AA$. As indicated by the SP mechanism (Scheme 3), 31,42 the $\mathrm{C} 6$ radical formed after photoexcitation of the $\mathrm{C} 5=\mathrm{C} 6$ bond then abstracts an $\mathrm{H}$ atom from the neighboring methyl moiety. Such an abstraction is highly feasible in the thymidine crystal as shown by the short distance revealed. This packing mode also suggests that only the excited $\mathrm{C} 5=\mathrm{C} 6$ bond in ring $\mathrm{b}$ is positioned to abstract the $\mathrm{H}$ atom from the $-\mathrm{CH}_{3}$ attached to ring a (Figure 2, B); the reverse direction is inhibited. Such a left-handed conformation thus determines that only the $5 S$ SP can be formed. Moreover, the $\mathrm{C} 5=\mathrm{C} 6$ bonds on adjacent thymidines are $4.86 \AA$ away from each other. Restricted by the crystal lattice, it is very difficult for them to move closer to enable the CPD formation. The reactive moieties involved in 6-4PP formation are even further away, indicating that the 6-4PP formation is also inhibited. Therefore, the thymidine crystal photoreaction should afford $5 S$ SP cleanly.

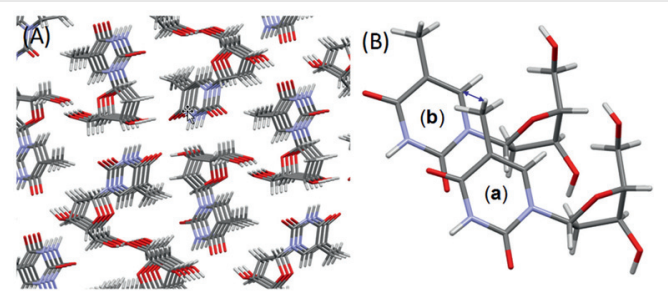

Figure 4 (A) Molecular packing in the thymidine single crystal. ${ }^{44}$ The distance between two thymidine rings is about 3.1 $\AA$, close to the average rise found in the A-form DNA. (B) The shortest distance between an $\mathrm{H}$ atom in $-\mathrm{CH}_{3}$ and the $\mathrm{C} 6$ of another thymine is about $3.2 \AA$ (blue arrow) that is even shorter than the $3.4 \AA$ found in a simulated DNA structure supporting SP photochemistry. ${ }^{45}$ Therefore, the thymidines in the crystal can support the key $\mathrm{H}$-abstraction step to initiate SP formation.

Indeed, irradiation of the thymidine crystals under 254 $\mathrm{nm}$ UV light for one hour results in a single product $5 S \mathrm{SP}$ in $\leq 0.1 \%$ yield; the only other species detected by HPLC is the unreacted thymidine. ${ }^{46}$ The low SP yield is likely owing to the fact that only layers at the crystal surface are exposed to UV light, while the bulk material is protected from reaction. To improve the reaction yield, the crystals were grinded into fine powder before UV light was applied. Under a constant agitation, the yield of $5 \mathrm{~S}$ SP was improved to about $1.0 \%$ after 24 hours under $254 \mathrm{~nm}$ UV light.

To further improve the yield, the thymidine microcrystal powder was suspended in methyl $t$-butyl ether (MTBE). Under $254 \mathrm{~nm}$ UV light, a reaction for 2.5 hours with constant agitation results in $5 S$ SP in $30 \%$ yield; the yield is further improved to $68 \pm 3 \%$ within 12 hours. ${ }^{46}$ Moreover, although the reaction under $302 \mathrm{~nm}$ UVB light was about sixfold slower, the resulting SP is more stable under UVB light; a yield of $84 \pm 2 \%$ was obtained after a reaction for 32 hours. Both yields represent a drastic improvement comparing with SP formation in other in vitro systems, where the maximum yield observed was about $1 \% .^{31,42}$

Although the thymidine crystal provides the "framework" for SP formation, it may not represent the optimal conformation as reflected by the " $S$ " shape sigmoidal curve (Figure 5) for reactions under both 254 and $302 \mathrm{~nm}$ light irradiation. The sigmoidal curve suggests that a "positive cooperativity" occurs among thymidine molecules in the crystal. A "nucleation" phase is likely present, which allows reaction "hot spots" to be formed to extend the interface between the reacted and unreacted regions in the crystalline lattice. ${ }^{47}$ When enough "hot spots" are produced, the reaction enters the "growth" phase until most material is consumed. The reaction then slows down to enter the "deceleration" phase. ${ }^{47}$ 


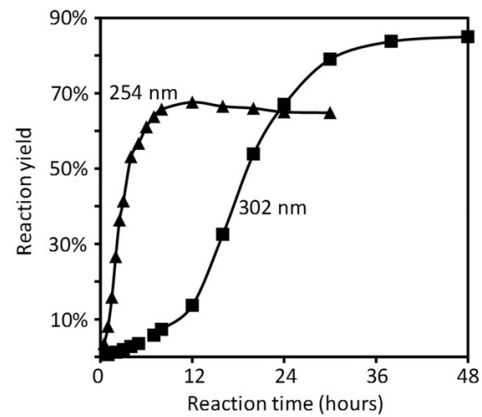

Figure 5 SS SP formation as a function of irradiation time for microcrystalline thymidine suspended in MTBE. $68 \%$ yield was achieved under $254 \mathrm{~nm}$ UVC; while about $85 \%$ yield can be obtained after 48 hours under 302 nm UVB light. The " $\mathrm{"} \mathrm{shape} \mathrm{sigmoidal} \mathrm{curve} \mathrm{for} \mathrm{both} \mathrm{reactions}$ suggests the presence of an "initiation" phase. A subtle conformational change in the thymidine crystal lattice induced by the formed SP molecules may occur, which consequently makes the SP formation even more favorable. The yield decrease after prolonged $254 \mathrm{~nm}$ UV irradiation is ascribed to possible SP decomposition.

\subsection{EPR Characterization of the Radical Intermedi- ates}

Because the photoreaction in thymidine crystals exclusively generates $5 S \mathrm{SP}$ as the sole product, the intermediates observed in the UV-irradiated thymidine crystals are most likely involved in SP formation. Therefore, by collaborating with Prof. Stefan Stoll's group at the University of Washington, Seattle, the radical intermediates formed in UV-irradiated thymidine microcrystals were monitored by EPR spectroscopy ${ }^{48}$ To confirm the nature of the possible radical species, four different thymidine isotopologues were utilized: unlabeled thymidine (thy), unlabeled thymidine with all exchangeable protons (i.e. N3 of the base and O3' and O5' of the sugar) replaced by deuterium (H/D-thy), $d_{3}$-thymidine with a $-\mathrm{CD}_{3}$ moiety (thy- $d_{3}$ ), and $d_{3}$-thymidine with all exchangeable protons replaced by deuterium (H/D-thy- $\mathrm{d}_{3}$ ) (Figure 6, left column). The microcrystals of these thymidine isotopologues were irradiated with a $266 \mathrm{~nm}$ laser at 120,210 , and $250 \mathrm{~K}$, and the resulting radical intermediates studied by EPR spectroscopy (Figure 6).

As shown in Figure 7, these thymidine isotopologues only generate two possible 5 - $\alpha$-thyminyl radicals $\left(\mathrm{TCH}_{2}\right.$ radical). However, depending on the source of the additional C6 hydrogen, four 5,6-dihydrothymin-5-yl radicals (TH radical) may be obtained. Here, three possible $\mathrm{H}$ resources may be identified: the thymidine methyl group (met), the exchangable hydrogens (EX) or other unknown hydrogens (0). To help decipher the EPR spectra shown in Figure 6, the EPR spectra of the six possible $\mathrm{TCH}_{2}$ and TH radicals were simulated (Figure 7). ${ }^{48}$

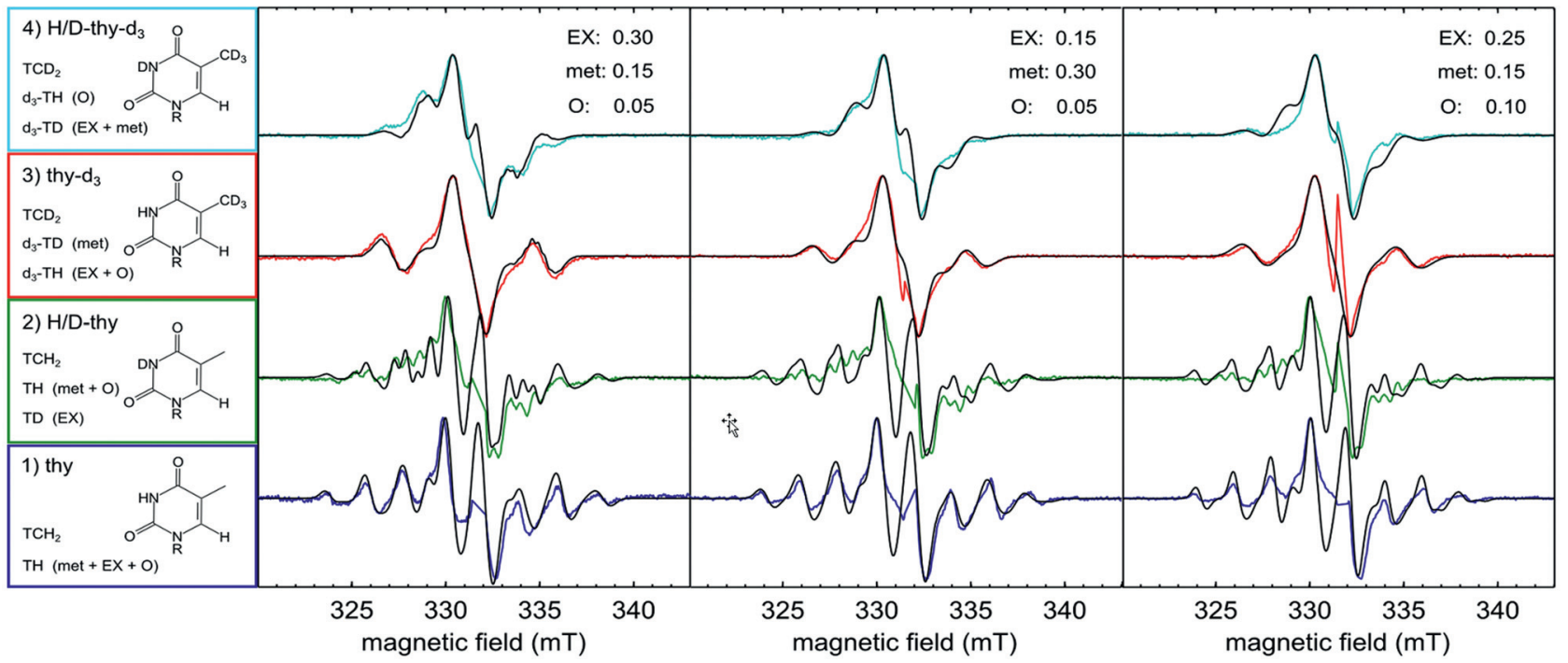

Figure 6 Continuous-wave EPR spectra of microcrystalline powder samples of thymidine (blue), H/D-thymidine (green), thymidine- $d_{3}$ (red), and H/Dthymidine- $d_{3}$ (cyan) irradiated with $266 \mathrm{~nm}$ laser pulses at 120, 210, and $250 \mathrm{~K}$. In all cases, EPR measurements were carried out at $120 \mathrm{~K}$. The structures of the starting materials are shown in the left column. The isotopologues of the $\mathrm{TCH}_{2}$ and $\mathrm{TH}$ radicals that are used to simulate the spectra are indicated to the left of each starting material. In addition, the hydrogen sources (met, EX, or O defined in main text) that lead to particular TH isotopologues for each starting material are indicated in parentheses. Simulations were performed assuming the restrictive model, and the fractions of hydrogen sources producing TH isotopologues at a given temperature of UV irradiation are indicated at the top right corner of each panel. Simulated spectra are shown in black. 


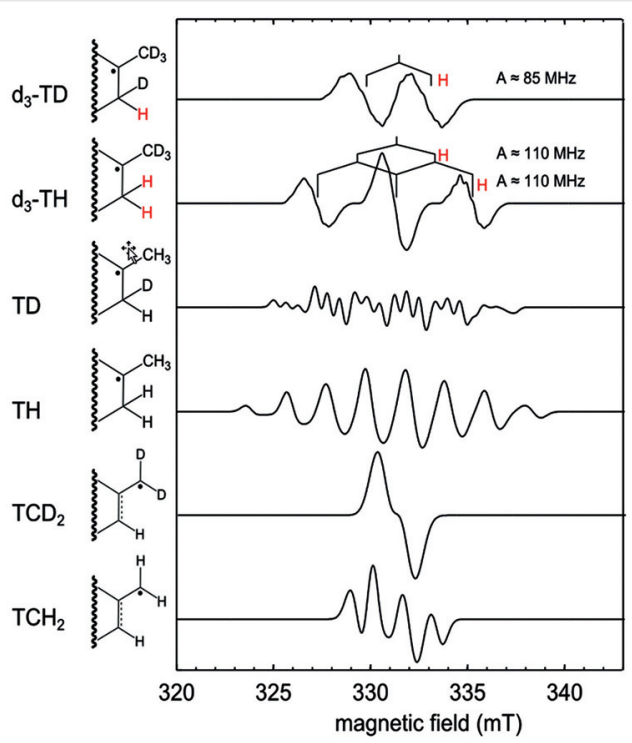

Figure 7 Simulations of the $9.3 \mathrm{GHz}$ EPR spectra of the two $\mathrm{TCH}_{2}$ isotopologues and four $\mathrm{TH}$ isotopologues that appear as components giving rise to the spectra of Figure 6

A "restrictive model" was then developed to quantitate the mixtures of $\mathrm{TCH}_{2}$ and $\mathrm{TH}$ isotopologues. As indicated by the numbers in each figure of Figure 6, various hydrogen resources contributed to different levels of TH radical formation at different temperatures. Overall, the methyl group is the major $\mathrm{H}$ source for $\mathrm{CH}$ radical formation, agreeing with the mechanism in Scheme 3. On the other hand, if the $\mathrm{TH}_{2}$ and $\mathrm{TH}$ radicals observed are "active" intermediates en route to SP formation, they should be close enough to induce coupling interactions in the EPR spectra. However, no such coupling interactions were found, indicating that the radicals observed represent "dead-end" species that, due to position restrictions, cannot recombine with other radicals, leading to SP formation. ${ }^{46,48}$ Furthermore, the TH radical formed through the "EX" pathway implies that electron transfer among thymidine residues also occurs, ${ }^{49}$ although that this process may not be involved in the SP photochemistry.

\section{Using a Phosphate Isostere to Understand the SP Structure}

After revealing the formation mechanism, the next question is to reveal how SP looks in the 3D space. As shown above, the dinucleotide context is a good work model for studying SP photochemistry. Dinucleotide SP possesses the size of a small organic molecule and may be relatively easily crystallized to provide valuable structural insights. However, different from organic molecules that are normally neutral, the dinucleotide SP TpT contains a negatively charged phosphodiester group. The charge is regarded to possibly interfere with molecular interactions in the crystal matrix, preventing the crystal formation.

A formacetal is the simplest and smallest nonchiral isostere for a phosphate moiety and has proved very useful in oligonucleotide biochemical studies. ${ }^{50,51}$ It is neutral and has enabled the successful crystallization of dinucleotide CPD analogs formed between two uracil ${ }^{51}$ and two thymine residues ${ }^{52}$. It may prove to be a good system for SP crystallization.

\subsection{Dry Film Photoreaction of Dinucleotide $\mathrm{T}_{\mathrm{CH} 2} \mathrm{~T}$ Fails to Generate any SP}

In previous studies, the dinucleotide analogs $\mathrm{T}_{\mathrm{CH} 2} \mathrm{~T}^{52}$ and $\mathrm{U}_{\mathrm{CH}_{2}} \mathrm{U}^{51}$ were synthesized. UVC irradiation of these compounds in aqueous solution generates the corresponding CPD species that were isolated by HPLC and subsequently crystallized by solvent evaporation. Moreover, the 6-4PP analog of $\mathrm{T}_{\mathrm{CH} 2} \mathrm{~T}$ was also prepared through prolonged UVC irradiation in aqueous solution. ${ }^{53}$

UV irradiation of TpT in dry film yields the corresponding SP. We thus synthesized $\mathrm{T}_{\mathrm{CH} 2} \mathrm{~T}$, dissolved it in methanol, and obtained a thin film after solvent evaporation. ${ }^{32}$ Irradiation of this film with $254 \mathrm{~nm}$ UV light, however, results in no SP. Since the outcome of DNA photoreaction is generally determined by the base-stacking conformation, ${ }^{54}$ the result indicates that the formacetal group likely interacts with the thymine bases in $\mathrm{T}_{\mathrm{CH} 2} \mathrm{~T}$, preventing the "correct" thymine stacking conformation to be formed. The neutral formacetal linker may not lead to the same conformer in the film, thus quenching the SP photochemistry.

\subsection{Synthesis of Dinucleotide $S P \mathrm{~T}_{\mathrm{CH} 2} \mathrm{~T}$}

The chemical synthesis of the dinucleotide SP TpT was already established, ${ }^{39}$ we then modified the procedure to prepare the SP analog with a formacetal linkage. The previous studies used SEM ([2-(trimethylsilyl)ethoxy]methyl) as

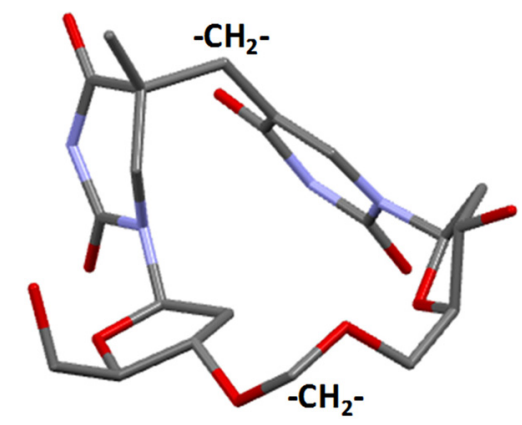

Figure 8 X-ray structure of the $5 R$ SP containing a formacetal linkage. Only the bridging methylene carbon between the two thymine bases and the formacetal linker carbon are labeled. 
a protecting group that is incompatible with the formacetal linkage in the $\mathrm{SnCl}_{4}$-promoted deprotection step; the benzyloxymethyl group $\left(\mathrm{CH}_{2} \mathrm{OBn}\right)$ was thus chosen for $\mathrm{N} 3$ protection as shown in Scheme $4 .^{32}$ After the LDA-mediated coupling step, the resulting $5 R$ isomer was isolated for the preparation of the $5 R$ SP analog. Similar reactions were conducted to prepare the $5 S$ isomer.
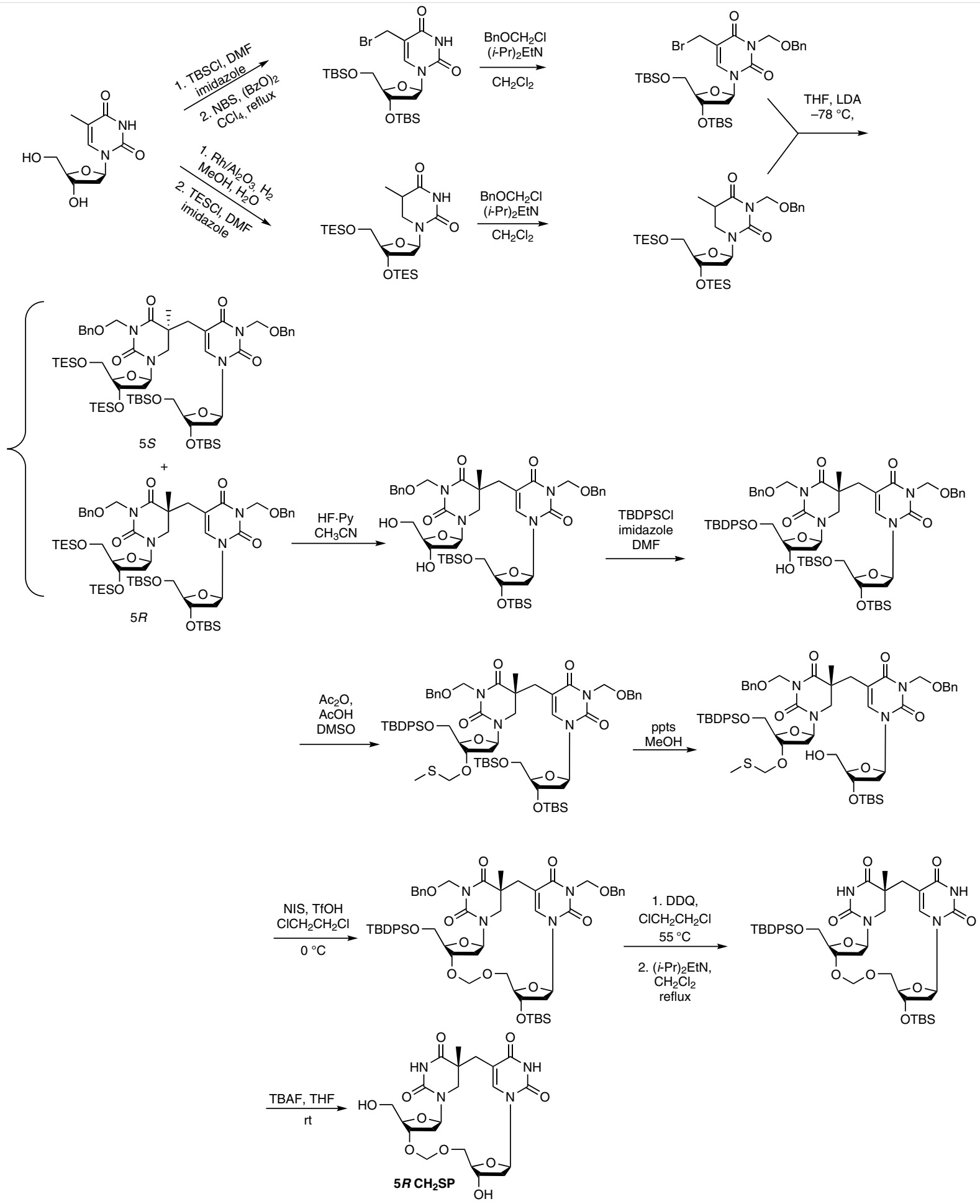

Scheme 4 Chemical synthesis of the SP analog containing a formacetal linkage 


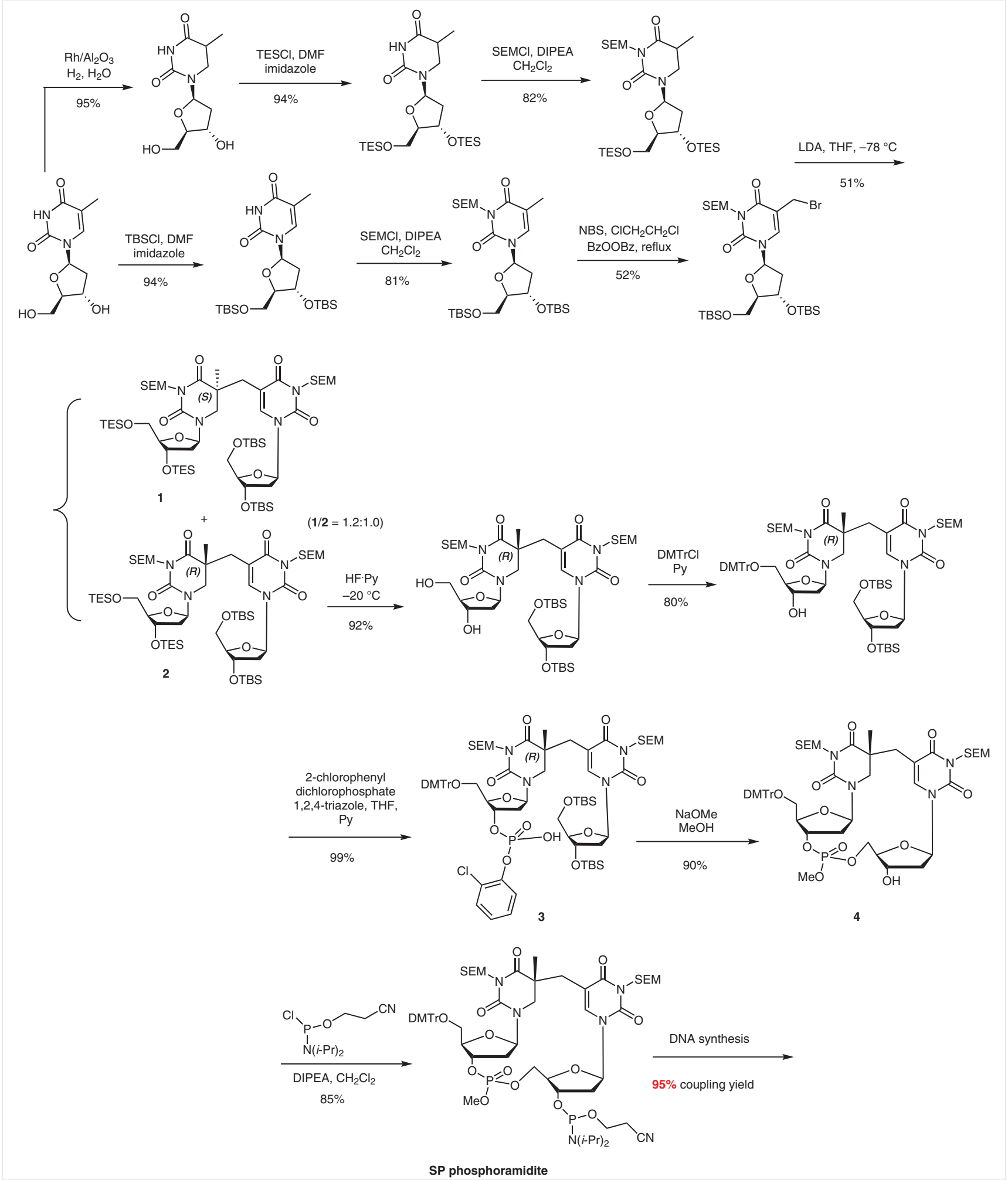

Scheme 5 Preparation of SP phosphoramidite for solid-phase oligonucleotide synthesis 
As expected, the neutral formacetal linker favors $5 R$ SP crystallization; the SP single crystal was readily formed after water evaporation. ${ }^{32}$ The structure shows that the two thymine moieties were connected by a $-\mathrm{CH}_{2}$ - linkage (Figure 8 ). Due to the loss of the $\mathrm{C} 5=\mathrm{C} 6$ bond, the resulting 5 'thymine ring is distorted; while the 3'-thymine ring is still planar as the ring aromaticity is still maintained. Although the two thymine rings are connected by the $-\mathrm{CH}_{2}$ - group, they still maintain some stacked conformation, indicating that formation of SP in duplex DNA may not lead to big local conformational changes. Attempts to crystallize the synthesized 5S SP isomer were unsuccessful. ${ }^{32}$

\section{Synthesis of SP Phosphoramidite and SP Structural Studies}

The dinucleotide SP $\mathrm{T}_{\mathrm{CH} 2} \mathrm{~T}$ structure indicates that SP may only cause minor changes to the duplex DNA structure. To gain further evidence supporting this assumption, an SPcontaining duplex DNA structure is preferred.

\subsection{Synthesis of the SP Phosphoramidite}

SP-containing oligonucleotides can be prepared by UV irradiation of DNA in the solid state. ${ }^{25,31,55}$ However, the yield of SP under such a treatment is very low $(<1 \%),{ }^{31}$ and the SP formation is accompanied by the formation of several other DNA lesions. To prepare SP-containing oligonucleotides in high purity, the use of SP phosphoramidite in solid-phase synthesis is a much more preferred approach.

The phosphoramidites of $\mathrm{CPD}^{56}$ and $6-4 \mathrm{PP}^{57}$ are available, enabling preparations of lesion-containing oligonucleotides. These phosphoramidites are generated by UV irradiation of protected dinucleotide TpT to produce the correspondent dimers before the phosphoramidite moiety is introduced. This approach, however, proves futile in the preparation of the SP phosphoramidite as once the phosphodiester moiety in TpT is protected by esterification, the resulting neutral dinucleotide no longer supports SP formation under UV irradiation. ${ }^{33}$

In contrast to CPDs and 6-4PPs, of which the chemical synthesis is not available, synthesis of dinucleotide SP TpT is successfully achieved. ${ }^{39}$ It is relatively straightforward to build on from this synthesis to prepare SP phosphoramidite as shown in Scheme 5. Comparing with the dinucleotide SP synthesis, the key to prepare SP-containing oligonucleotides in acceptable yields is to replace the 2-chlorophenyl protecting group at the phosphodiester moiety with a small methyl group. ${ }^{33}$ Such a replacement $(\mathbf{3} \rightarrow \mathbf{4})$ improves the coupling efficiency from about $15 \%$ to about $90 \%$; this is possibly due to the removal of the steric hindrance caused by the bulky chlorophenyl moiety. ${ }^{33}$

\subsection{Structural Studies of an SP-Containing Duplex Oligonucleotide}

The availability of SP-containing oligonucleotides makes the structural studies of SP-containing duplex DNA possible. By collaborating with Prof. Millie Georgiadis' laboratory at the Indiana University School of Medicine, a SP-containing 16-mer self-complimentary duplex (5'-ATCCGSPATAACGGAT-3') was crystallized by using a so-called host-guest approach. ${ }^{58}$ This approach uses the $\mathrm{N}$-terminal fragment of Moloney murine leukemia virus reverse transcriptase (MMLV RT) as the host to bind the 16-mer oligonucleotide; the resulting nucleoprotein complex is then crystallized under well-established experimental conditions. As a control, the undamaged 16-mer oligonucleotide with the same sequence was also crystallized. ${ }^{34}$

(A)

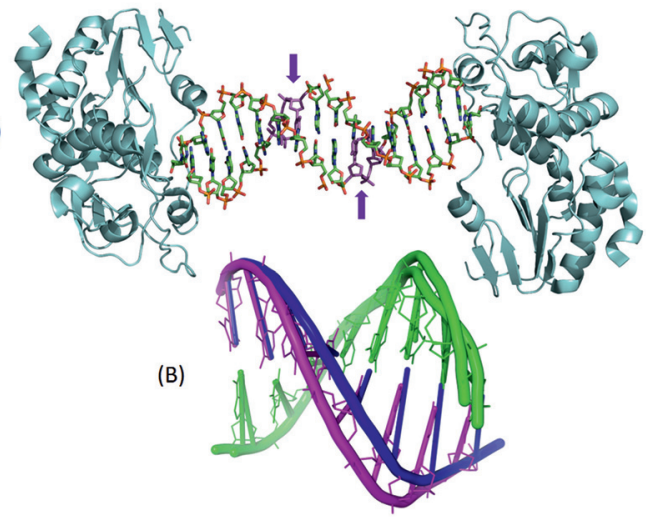

Figure 9 (A) Crystal structure of the nucleoprotein complex with two MMLV RT molecules (cyan) and one 16-mer oligonucleotide. ${ }^{34}$ The asymmetric unit of the complex includes one protein molecule and eight base pairs of the duplex oligomer. The two SPs are shown in magenta and pointed by two magenta arrows. (B) Superimposed structures of the eight-bp asymmetric oligonucleotide unit of the undamaged oligomer (in blue, pdb entry 4M95) and the SP TpT-containing oligomer (in magenta, pdb entry 4M94). The minor groove is widened from $9.7 \AA$ in the undamaged strand to $12.5 \AA$ in the SP-containing strand.

The 16-mer duplex oligonucleotide maintains the BDNA conformation (Figure 9, A). In contrast to CPDs and 64PPs which disrupt $\mathrm{H}$-bonding interactions with the two adenines on the complementary strand, ${ }^{21,59,60}$ the SP lesion retains all Watson-Crick hydrogen bonds. Moreover, the hydrogen bonds in the SP-AA pairs are even shorter than those found in the undamaged DNA. As shown in Figure 9, $\mathrm{B}$, the undamaged DNA structure can be overlain almost perfectly with the SP-containing 16-mer structure except for the region surrounding the lesion where duplex unwinding at the SP site followed by overwinding at the next three nucleotides occurs, causing the minor groove to be widened by almost $3 \AA$ A. However, comparing with DNA structural changes induced by a $\mathrm{CPD}^{21,59}$ or a $6-4 \mathrm{PP}^{60}$ lesion, the changes induced by SP are the smallest. ${ }^{21}$ On the other 
hand, the CPD and 6-4PP studies used oligonucleotides containing only one lesion; while the SP study used a 16-mer oligonucleotide containing two SPs. The possibility that the two SPs may have concerted impacts on the overall oligonucleotide conformation cannot be excluded.

Although the DNA conformational changes induced by SP were suggested to be possibly responsible for lesion recognition by SPL in germinating spores, ${ }^{34}$ the latest enzymology data imply that these changes may not be sufficient enough to warrant a recognition and a subsequently rapid SP repair. ${ }^{29}$ In germinating spores, other factors such as the unique spore DNA conformation or other SP recognition proteins may also be involved in the SP repair. It was shown that SP is several 100 -fold more effective to induce mutations than undamaged DNA. ${ }^{61}$ With SP-containing oligonucleotides being available, we are now ready to decipher the SP mutation spectrum in the close future.

\section{Using a Thymine Isostere to Understand CPD Formation}

The SP mechanism shown in Scheme 3 indicates that the two involved thymine residues have distinct roles: one thymine molecule (the 5'-thymine if in the oligonucleotide context) needs to be excited to form a diradical and the other thymine can simply be the methyl donor regardless of its excitation state. It is thus of interest to reveal whether a methyl donor other than a thymine can facilitate SP photochemistry.

\subsection{A Toluenyl Moiety Does Not Support SP Forma- tion in Dry Film Photoreactions}

Toluenyl (To) moieties are close steric analogs of thymine. Especially, the nonpolar 2,4-difluorotoluene residue possesses a nearly identical size and shape of T; ${ }^{62,63}$ DNA polymerases can readily incorporate it into DNA as if it were thymine. ${ }^{63,64}$ We wonder whether an SP analog can be formed in the dinucleotide analog TpTo that contains an excitable $\mathrm{T}$ at the 5 '-end and a methyl-donating To at the 3'-end.

Unfortunately, after evaporation of the methanol or aqueous solution of TpTo, irradiation of the resulting film under $254 \mathrm{~nm}$ UV light leads to no obvious photoproduct formation. In aqueous solution, the toluenyl moiety is likely to stack on the neighboring thymine to minimize the exposure area of the hydrophobic toluenyl ring to water. Such a requirement is no longer needed in the dry film. Since stacked nucleobases are required for the formation of pyrimidine dimers, we tentatively conclude that the lack of stacked conformers or the lack of reactive conformation is responsible for the lack of formation of SP analogs.

\subsection{Formation of CPD Analogs in the TpTo Photo- reaction in Ice}

When irradiating TpTo in ice under $254 \mathrm{~nm}$ UVC light, two new products are found. ${ }^{36}$ Structural characterization by NMR spectroscopy shows that both products contain a cyclobutane ring between $\mathrm{T}$ and $\mathrm{To}$, indicating that they are formed through the $[2+2]$ photoaddition mechanism, similar to the formation of dipyrimidine CPDs. Interestingly, different from dipyrimidine CPDs in which the two $\mathrm{C} 5=\mathrm{C} 6$ bonds dimerize, the CPDs formed in the TpTo photoreaction involve the $\mathrm{C} 5=\mathrm{C} 6$ bond from the $\mathrm{T}$ and the $\mathrm{C} 4=\mathrm{C} 5$ bond (product 1 ) or $\mathrm{C} 3=\mathrm{C} 4$ bond (product 2 ) from the To moiety (Scheme 6, A). This result implies that symmetric to the C1C4 axis, either side of the toluenyl ring can stack on the thymine ring. If the toluenyl moiety is replaced by a xylenyl (X) ring, the resulting dinucleotide TpX only supports the formation of one CPD product (product 3 ) because the steric hindrance between the 2-methyl group and the 2'-deoxyribose of $\mathrm{X}$ inhibits the formation of the other product (Scheme 6, B).

Moreover, just like regular CPDs, the CPD formation in TpTo and TpX photoreactions is reversible. ${ }^{35}$ Between the two products generated from the TpTo photoreaction, the quantum yield of $\mathbf{1}$ is 1.7 -fold higher than that of $\mathbf{2}$. Because the outcome of DNA photoreactions is largely determined by the nucleobase stacking conformation before UV excitation, ${ }^{54,65}$ the conformer responsible for the formation of $\mathbf{2}$, in which the toluenyl methyl group may hydrophobically interact with the thymine ring, is $0.11 \mathrm{~kJ} \mathrm{~mol}^{-1}$ more stable at $77 \mathrm{~K}$ than the conformer responsible for the formation of $\mathbf{3}^{35}$

The CPD structures from the TpTo and TpX photoreactions indicate that although the substituted toluene closely mimics the size and shape of thymine, ${ }^{62,63}$ its stronger hydrophobicity may change the DNA local structure by rotating about $60^{\circ}$ away from the TpT conformation. More interestingly, toluene or substituted toluene possesses rather different electronic structures from that of thymine due to their higher symmetries, absence of the $n \pi^{*}$ states, and lack of tautomeric structures, ${ }^{3,66}$ making them rather photoinert. Therefore, in $\mathrm{TpTo} / \mathrm{TpX}$, only the thymine residue is likely excited by the $254 \mathrm{~nm}$ UV light. The fact that CPDs are still formed here indicates that the CPD photochemistry only requires excitation of one of the involved pyrimidine residues.

\section{Using a Thymine Isostere to Understand 6-4PP Photoreaction}

UV irradiation of natural dipyrimidine sequences always results in a mixture of photoproducts. For instance, irradiation of TpT in aqueous solution results in both CPD and 6-4PP. In contrast, the TpTo and TpX photoreactions only generate CPDs. Specifically, irradiation of TpX produces a 

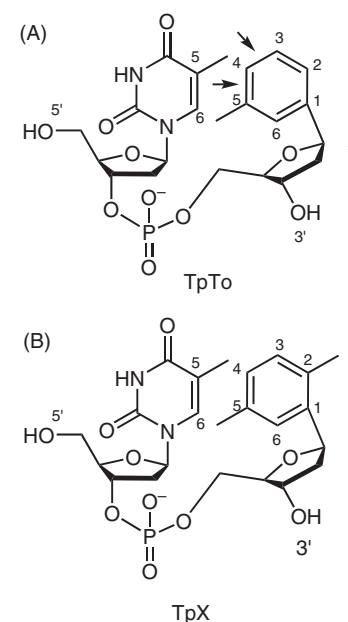
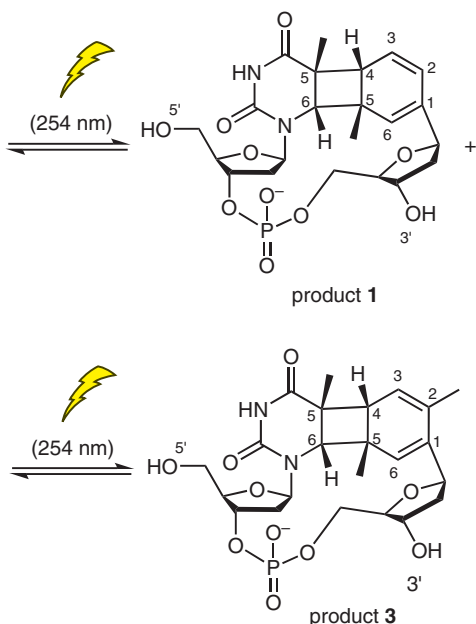
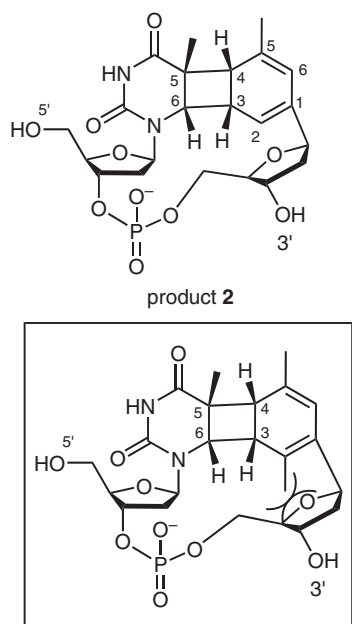

Scheme 6 (A) Chemical structures of the two CPD analogs generated from the TpTo photoreaction. No other species, such as an SP analog, was detected. Similar to CPD formation between two natural pyrimidine residues, the CPD formation in the TpTo photoreaction is also reversible. However, different from the $C P D$ s from dipyrimidine photoreactions where the two $C 5=C 6$ bonds dimerize into a cyclobutane ring, the CPDs formed here involve the $\mathrm{C} 5=\mathrm{C} 6$ from $\mathrm{T}$ and the $\mathrm{C} 3=\mathrm{C} 4$ or $\mathrm{C} 4=\mathrm{C} 5$ from To. (B) In contrast, photoreaction of the dinucleotide TpX only results in one photoproduct (product 3 ). The steric hindrance between the 2-methyl group and the 2'-deoxyribose in To prevents the formation of the other product.

single CPD species in a very clean manner. Because the $5^{\prime}$ and the 3 ' residues in a dipyrimidine step are spatially different due to the oligonucleotides' right-handed chirality, it is of interest to reveal whether the reaction pattern changes after switching the $\mathrm{T}$ and $\mathrm{X}$ in the dinucleotide context.

Interestingly, UV irradiation of the resulting dinucleotide XpT also generates two major products, both of which exhibit an UV absorption at about $320 \mathrm{~nm}$, indicating that they both contain a pyrimidone ring found in the natural 64 PP. ${ }^{37}$ No CPD or true SP analog (with a methylene bridge between $\mathrm{C} 5$ of $\mathrm{X}$ and $\mathrm{C} 5$ of T) was found. Product 1 is identified as a $6-4 \mathrm{PP}$ analog (Scheme 7). Product 2 contains a methylene bridge formed from the 5-methyl moiety of $\mathrm{X}$ that is added to the thymine ring at the $C 4$ position. Since the only naturally occurring thymine dimer that contains a methylene bridge is SP, this product is named an SP analog. The chemical structures imply that both products are formed from reactions involving the thymine $\mathrm{C} 4=0$ moiety.
To understand the chemical mechanism behind this XpT photoreaction, quantum-chemical calculations were conducted in collaboration with Prof. Tatiana Domratcheva's group at the Max-Planck Institute for Medical Research, Heidelberg, Germany. ${ }^{37}$ The calculations indicate that the rather photoinert but electron-rich xylenyl ring readily donates an electron to the photoexcited 3'-thymine residue, resulting in a pair of transient radical cation and anion. The formation of these intermediates lowers the energy in the formation of interbase covalent bonds eventually yielding the 6-4PP and the SP analogs.

Only the thymine ring is likely to be photoexcited in the XpT photoreaction. The excitation of the 3'-T seems sufficient enough to enable the reaction at $\mathrm{C} 4=\mathrm{O}$, leading to the formation of the 6-4PP. This result, together with our previous studies on the formation of cyclobutane pyrimidine dimers (CPDs) and SP described above, indicates that exci-

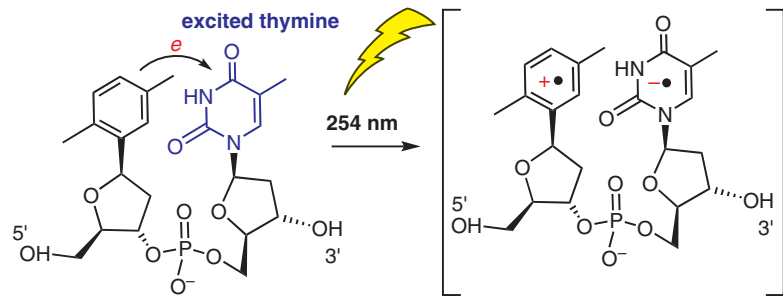

XpT

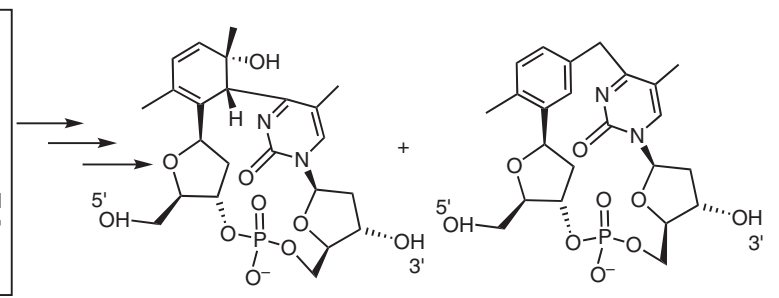

6-4PP analog
SP analog

Scheme 7 Chemical structures of the two photoproducts formed in the XPT photoreaction under $254 \mathrm{~nm}$ UV light. Product 1 is a 6-4PP analog. Product 2 involves a xylenyl methyl group and is named an SP analog as SP formation also involves a thymine methyl group. Both reactions involve the C4=O moiety at the thymine. Quantum-chemical calculations imply that upon UV excitation, the thymine ring accepts an electron released by the xylenyl ring, generating a pair of transient thyminyl anion and xylenyl cation intermediates. Subsequent reactions of these species lead to the formation of the 6-4PP and SP analogs. 
tation of a single "driver" residue is sufficient to trigger pyrimidine dimerization, and this is likely a general model for all three pyrimidine photoreactions.

\section{Understanding the Chemical Stability of SP}

As the genetic information carrier, the genomic DNA needs to maintain its chemical and physical stability. Formation of pyrimidine dimers is often accompanied with DNA strand breaks, indicating that the photolesions may weaken the otherwise stable DNA backbone. However, how nucleobase modifications trigger reactions at the 2'-deoxyribose to break the DNA backbone remain ill defined. It is thus of significance to understand the basic chemical reactivity of DNA photolesions to shed light on the mechanisms involved in the conversion of a simple nucleobase modification into an act of DNA cleavage.

Treatment of lesion-containing oligonucleotides with $0.1 \mathrm{M} \mathrm{NaOH}$ or $1 \mathrm{M}$ piperidine at an elevated temperature is often used to induce strand cleavage, ${ }^{67}$ which is then used as a function assay to reveal the presence of certain lesions in the oligomeric DNA. To understand the chemical stability of SP, we first treated the dinucleotide SP TpT with $0.2 \mathrm{M}$ $\mathrm{KOH}$ at ambient temperature and found that such a treat- ment results in a single product, an SP hydrate. ${ }^{68}$ Interestingly, this hydrolysis reaction is reversible under basic conditions; the equilibrium determines that there is always some SP left in the reaction solution. ${ }^{68}$ When the reaction is carried out in ${ }^{18} \mathrm{O}$-labeled water containing $0.2 \mathrm{M} \mathrm{KOH}$, the ${ }^{18} \mathrm{O}$ label is quickly incorporated into the remaining SP as shown by ESI-MS spectrometry. Moreover, the newly formed SP hydrate at the very beginning only carries one ${ }^{18} \mathrm{O}$ label; prolonged incubation converts all SP hydrate into the doubly- ${ }^{18} \mathrm{O}$-labeled species. This observation is best explained by the reversible formation of a tetrahedral gemdiol intermediate at the $\mathrm{C} 4$ position of the 5'-thymine that is saturated due to the addition of the methylene group to the $\mathrm{C} 5$ (Scheme 8). At pH 7.4, this gem-diol intermediate is still formed as implied by the incorporation of ${ }^{18} \mathrm{O}$ into SP albeit at a slower rate, suggesting that the intermediate and the subsequent ring-opened SP hydrate may form in a live cell when SP is present in the genomic DNA. ${ }^{68}$

The SP formation from the reversal of SP hydrate in a basic solution is surprising as that requires an ureido group being added to the carboxyl moiety. It is rare for a direct amidation of carboxylic acids to occur without catalysis because the carboxyl moiety is not a good electrophile due to the negative charge it carries. Detailed studies of the SP reversible hydrolysis in the presence of $0.2 \mathrm{M} \mathrm{KOH}$ determine<smiles>CC1(Cc2cn(CCO)c(=O)[nH]c2=O)CN(C2OC3COC2(CO)OP(=O)([O-])O3)C(=O)NC(=O)C1O</smiles>

unlabeled SP

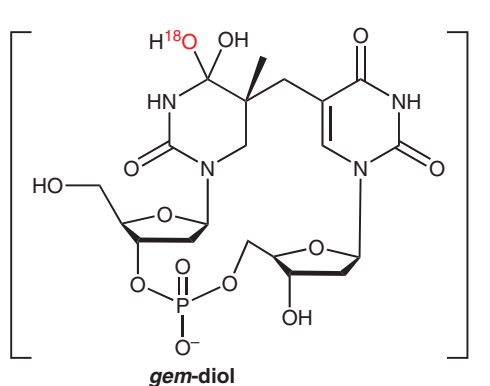

gem-diol

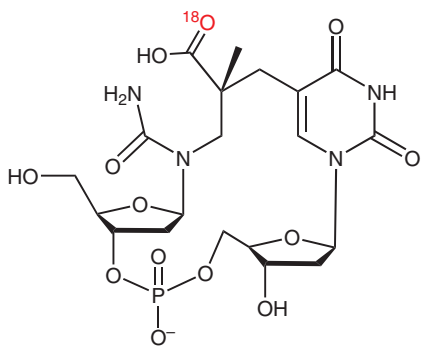

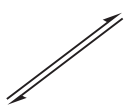

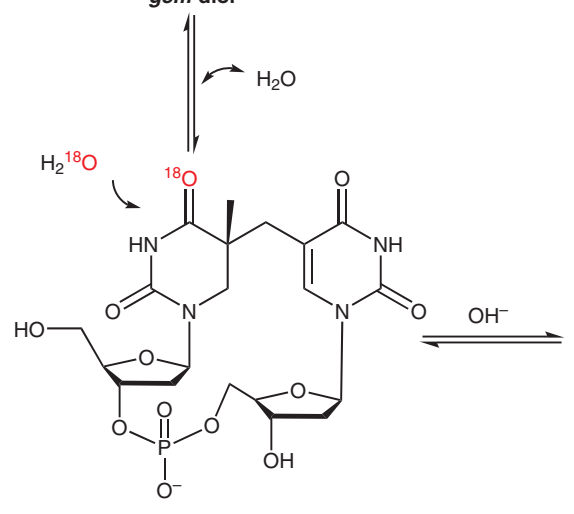

${ }^{18}$ O-labeled SP

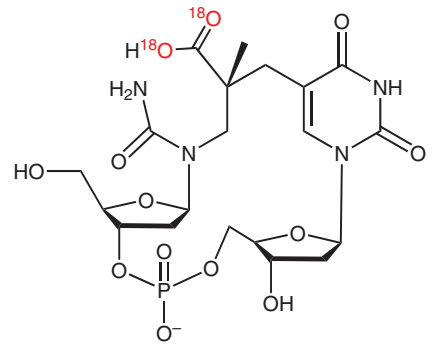

double- ${ }^{18} \mathrm{O}$-labeled SP hydrate<smiles>C=C</smiles>

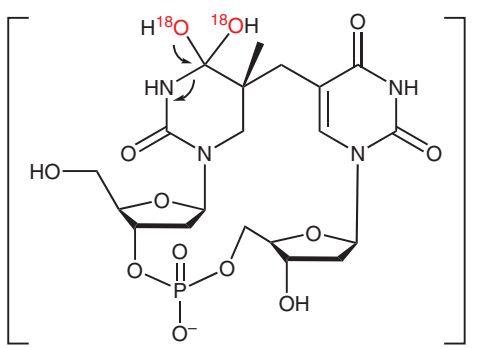

gem-diol

Scheme 8 Formation of an SP hydrate during the alkaline treatment of SP in ${ }^{18} \mathrm{O}$-labeled water. SP and its hydrate are in equilibrium with the reaction conditions used. As monitored by ESI-MS spectrometry, SP quickly exchanges with water to subsequently carry an ${ }^{18} \mathrm{O}$ label and the newly formed SP hydrate also carries an ${ }^{18} \mathrm{O}$ label at the very beginning of the reaction. A prolonged incubation eventually converts all SP hydrate into the double- ${ }^{18} \mathrm{O}-$ labeled species. These observations indicate the formation of a gem-diol intermediate at the $C 4=0$ of the 5 '-thymine residue that subsequently leads to the rupture of the N3-C4 bond yielding the SP hydrate. 
a $\Delta \mathrm{H}$ of $-14.87 \pm 1.5 \mathrm{~kJ} \mathrm{~mol}^{-1}$ and a $\Delta \mathrm{S}$ of $-43.24 \pm 3 \mathrm{~J} \mathrm{~mol}^{-1}$ $\mathrm{K}^{-1}$, which imply that although kinetically favorable at an elevated temperature, the equilibrium disfavors the ringopening reaction to form an SP hydrate. Therefore, the SP formed in the genomic DNA is to some extent protected from undergoing such a ring-opening process, thus helping maintain the integrity of the spore genome.

Although SP hydrate formation is somewhat inhibited by the unfavorable equilibrium, it may still form in the genome that may subsequently lead to DNA strand cleavage. To reveal how this process may occur, the SP hydrate is isolated and heated to $90{ }^{\circ} \mathrm{C}$ for 0.5 hour in a buffer at neutral $\mathrm{pH}^{67}$ Monitoring the reaction by ESI-MS reveals the presence of two intermediates before the DNA backbone is cleaved (Scheme 9). The mechanism thus provides a detailed picture on how SP may be responsible for DNA strand scission that was observed in UV irradiated endospores. ${ }^{69}$

\section{Understanding the Chemical Stability of 6-4PP}

The base lability of SP indicates that similar reactions may occur with other pyrimidine lesions. 6-4PP is long known to be base labile. ${ }^{70}$ This induced strand cleavage offers a functional assay for the analysis of 6-4PP formed in the genomic DNA, ${ }^{71}$ although some studies question whether $6-4 \mathrm{PP}$ is truly alkaline labile. ${ }^{72,73}$ It was reported previously that alkaline treatment of 6-4PP results in a similar hydration product possible via the gem-diol intermediate at the C4 followed by rupture of the N3-C4 bond. ${ }^{72,74}$ Our group, however, demonstrated that the 6-4PP hydrate may not be stable enough to be detected as it undergoes a rapid esterification reaction facilitated by the 5-OH group, resulting in a stable 2-oxazolidinone (5-4) pyrimidone product after eliminating a molecule of ammonia (Scheme 10). ${ }^{75}$

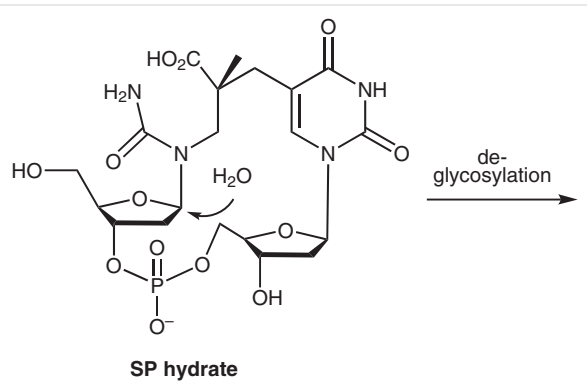<smiles>CC(C)(CNC(N)=O)Cc1cn(C2CC(O)C3(COP(=O)([O-])OC4CC(O)CC2O4)OCC3O)c(=O)[nH]c1=O</smiles>
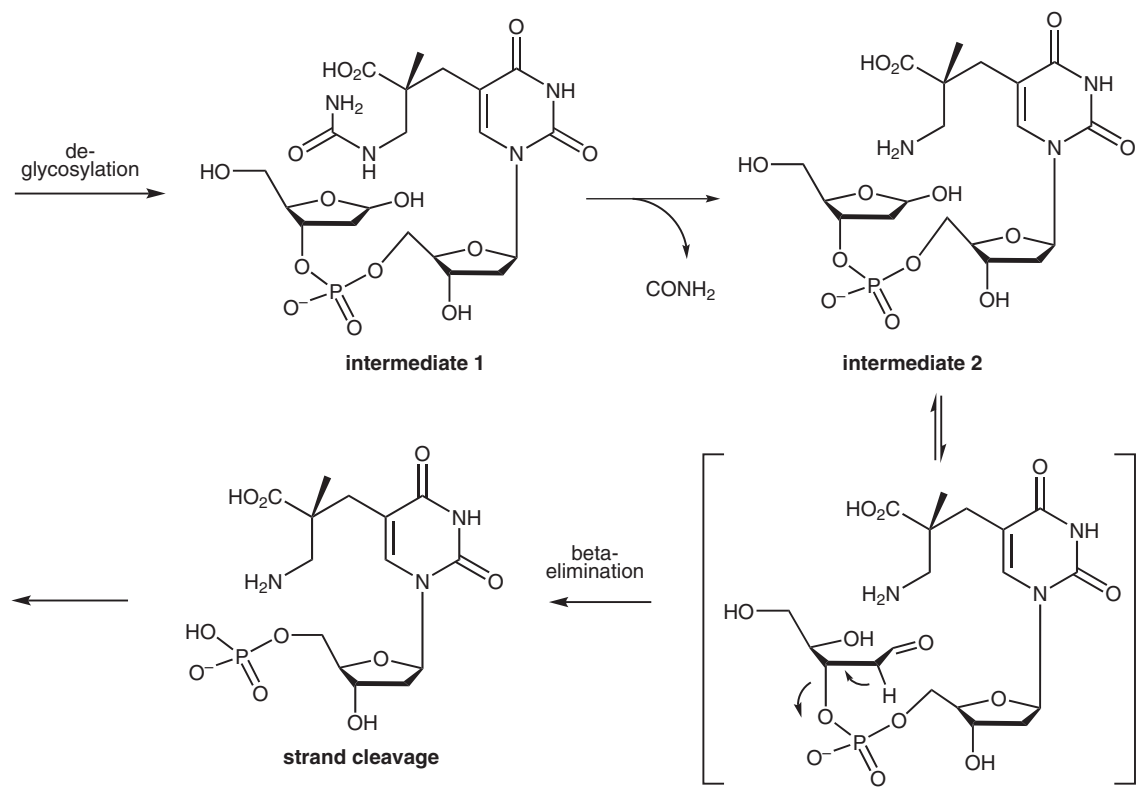

Scheme 9 The SP hydrate-mediated DNA strand cleavage reaction at physiological pH. Two reaction intermediates were observed by ESI-MS spectrometry, providing a detailed picture on how SP formation may lead to the strand cleavage.

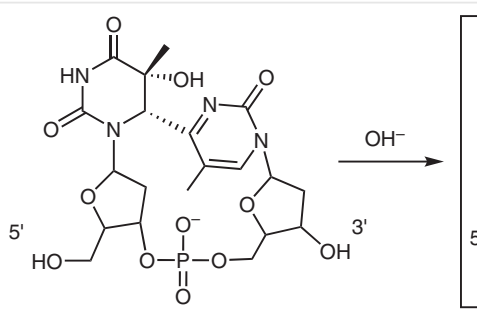

6-4PP

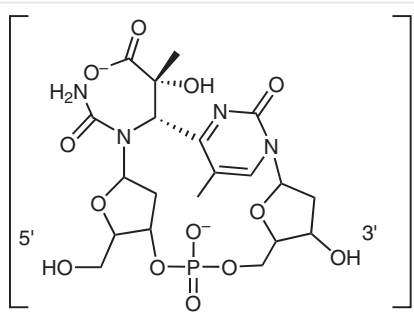

6-4PP hydrate

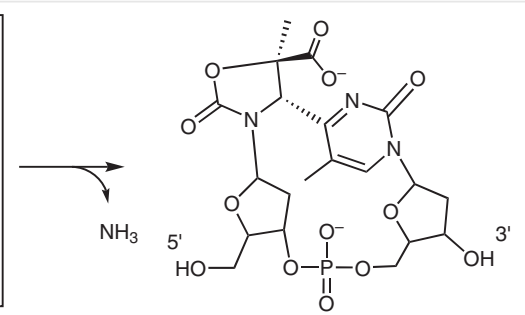

2-oxazolidinone (5-4) pyrimidone

Scheme 10 6-4PP hydrolysis under strong alkaline conditions. The putative 6-4PP hydrate formed via a similar gem-diol intermediate is unstable; it quickly undergoes an esterification/deamination process due to the presence of the 5-OH group in 6-4PP, yielding 2-oxazolidinone (5-4) pyrimidone as a stable final product. 
The reaction is in sharp contrast to the aforementioned reversible SP hydrolysis reaction. Since the putative 6-4PP hydrate was not observed under the reaction conditions used, it is unclear whether the hydrolysis is reversible. However, the deamination/esterification step leading to 2oxazolidinone (5-4) pyrimidone is irreversible, which then drives the reaction to completion. The ring-opening reaction upon base treatment was also observed with 5,6-dihydro-2'-deoxyuridine ( $\mathrm{dHdU}$ ), and the reaction produces a stable dHdU hydrate resulting from the decomposition of the gem-diol intermediate. Therefore, even though the gemdiol formation appears to be a common mechanism associated with a saturated pyrimidine ring, the different reactivity exhibited by SP, 6-4PP, and dHdU suggests that the stability of a saturated pyrimidine residue is largely controlled by the very chemical structure of the lesion.

\section{Summary and Perspectives for Future Research}

In summary, our research in the past eight years on pyrimidine dimers, especially on SP, illustrates what synthetic chemistry can do to help advance our understanding on the formation mechanisms of DNA photolesions. The deuterium labeling strategy enabled by synthetic chemistry allows us to firmly establish the SP formation mechanism, solving a controversy that had been puzzling the DNA photochemical field for nearly 40 years. Previous DNA photochemical studies used natural thymine and cytosine residues, both of which can be excited upon UV irradiation. By substituting a thymine with a photoinert toluenyl or xylenyl moiety, we are able to distinguish the two involved pyrimidines and obtain clear evidence that both CPD and 6-4PP formation require excitation of only one of the pyrimidine residues. Therefore, the two seemingly identical pyrimidine residues may play distinct roles in pyrimidine photochemistry. Moreover, the electron-rich xylene facilitates electron donation but impedes electron acceptance. Therefore, in the XpT dinucleotide, only 5' to 3' ET may occur that leads to 64PP formation, thus providing unambiguous experimental evidence that 6-4PP photochemistry is initiated by the 5'to-3' but not the 3'-to-5' ET process.

Despite the progress made, various questions on the pyrmidine dimerization mechanism still remain. For instance, CPDs and 6-4PPs can be formed in any dipyrimidine step, while SP is only found between two thymine residues. ${ }^{21}$ However, the $\mathrm{C}=\mathrm{C}$ moiety in a cytosine can also be excited to a diradical under UV irradiation. According to the proposed SP mechanism, the C6 radical of the 5'-C may readily abstract an $\mathrm{H}$-atom from the methyl group of the 3'-T residue and the resulting C5 and methyl radicals may recombine to yield an SP in the CpT step. Why such SP CpT photochemistry does not occur in nature is unclear. Moreover, interbase electron transfer between the two involving pyrimidine residues has been indicated to be essential for 6-4PP formation as studied in the dinucleotide context. ${ }^{11}$ Electron transfer from the neighboring nucleotides to the dipyrimidine step likely occurs in the genomic DNA. How the redox property of these "neighbors" may alter the CPD or 6-4PP photoreaction in the dipyrimidine step is also unknown. To address these questions, longer DNA strands containing certain sequences or certain chemical modifications are needed, which again can be prepared through organic synthesis.

In addition to the elucidation of lesion formation mechanisms, our studies have also created tools for better understanding of the general SP photobiology. Our SP phosphoramidite for the first time enables SP incorporation into oligonucleotides with high purity, paving the way for studying the SP impacts to the genome function/stability. Using SPcontaining duplex oligonucleotides, we obtained a crystal and solved the structure that shows that SP only induces very minor conformational changes. Thymine dimers are mainly repaired by the nucleotide excision repair (NER) pathways in vegetative cells that rely on lesion-induced DNA conformational changes for substrate recognition. ${ }^{76}$ Thus, the observed small changes suggest that SP may be difficult to be recognized by NER in B-DNA and its repair in resulting vegetative cells is likely slow. Subsequently, a large portion of SPs may survive the repair process and lead to mutations during error-prone lesion bypass events. SP is implied to be highly mutagenic and its mutation spectrum is unknown. ${ }^{61}$ The synthesized SP-containing oligonucleotides will enable detailed polymerase bypass studies to shed light on the SP mutation properties.

Besides those mentioned above, our studies described here also suggest that organic synthesis and chemical analysis have the potential to enable the development of many other highly useful "toolsets" that may allow the understanding of DNA photobiology in unprecedented details. In this vein, we tentatively bring out two directions to illustrate what may be done in the future.

Firstly, lesion-specific antibodies have played important roles in the development of DNA photobiology. The CPD and 6-4PP antibodies were generated almost forty years ago; ${ }^{77}$ they have enabled numerous CPD and 6-4PP biological studies in various organisms including rodents ${ }^{78}$ and humans ${ }^{79}$ with use of assays such as immunostaining and immunoprecipitation. However, the currently available CPD antibodies mainly recognize the cyclobutane structure; they cannot effectively distinguish the four CPDs formed in a specific dipyrimidine step, that is TT, TC, CT, or CC. Similar problems are also true with the 6-4PP antibodies. So far, no SP antibodies have been reported. Currently, immunology has reached a stage that allows the development of antibodies capable of distinguishing small structural differences in antigens. For example, monoclonal antibodies specifically recognizing 5-methycytosine $(5 \mathrm{mC})$ are now commercially available, proving that it is highly feasible to develop 
antibodies distinguishing the small structural difference between a $\mathrm{T} / \mathrm{C}$ and a $5 \mathrm{mC}$. Therefore, it is feasible to develop antibodies recognizing a specific pyrimidine dimer. In order to make it work, oligonucleotides (prepared by synthetic chemistry) contain a well-defined pyrimidine dimer are needed as the antigen for immunization. This, coupled with the careful antibody screening after immunization, should allow the preparation of antibodies with a much enhanced specificity.

Secondly, comparing with antibody-based immunoassays that may suffer from nonspecific antibody binding and/or weak binding induced by DNA secondary structures, the "holy grail" for genome-wide DNA photolesion analysis is to harness the power of lesion-specific chemistry for lesion labeling to enable lesion enrichment and minimize the structural bias. As demonstrated by the recent seminal work of 8-oxo-7,8-dihydroguanine (OG) sequencing analysis from Burrows' group, the lower redox potential of OG (about $600 \mathrm{mV}$ lower than $\mathrm{G}$ ) was utilized to allow the selective oxidation of OG without touching the undamaged G. The resulting electrophilic OG oxidation product can then be labeled by amine-terminated biotin, allowing the specific pulldown of modified DNA fragments through biotinstreptavidin interactions for subsequent high-throughput sequencing anlysis. ${ }^{80}$

The successful development of the OG analytical assay is based on the good understanding of the redox properties of OG. Any given DNA lesion may possess some unique chemical properties, the understanding of which may enable targeted lesion chemical modifications, subsequently allowing selective enrichment of lesion-containing DNA fragments. As shown in our alkaline treatment of SP, 6-4PP, and dHdU, these lesions exhibit very different chemical stability under basic conditions, even though they all pass through the same gem-diol intermediate before ring-opening occurs. This stability difference may allow us to design assays to specifically target a given lesion. It is our hope that by thoroughly understanding the reactivity difference among pyrimidine dimers as well as other DNA lesions, genome-wide lesion mapping can be achieved in the close future.

\section{Acknowledgment}

I thank my co-workers and my wonderful collaborators who contributed to this research and whose names are shown in the references. The work is supported in part by the National Science Foundation (CHE1454184) and in part by the Research Scholar Grant (RSG-16040-01-DMC) from the American Cancer Society.

\section{References}

(1) (a) Brash, D. E. Photochem. Photobiol. 2015, 91, 15. (b) Hodis, E.; Watson, I. R.; Kryukov, G. V.; Arold, S. T.; Imielinski, M.; Theurillat, J.-P.; Nickerson, E.; Auclair, D.; Li, L.; Place, C.; DiCara, D.; Ramos, A. H.; Lawrence, M. S.; Cibulskis, K.; Sivachenko, A.;
Voet, D.; Saksena, G.; Stransky, N.; Onofrio, R. C.; Winckler, W.; Ardlie, K.; Wagle, N.; Wargo, J.; Chong, K.; Morton, D. L.; Stemke-Hale, K.; Chen, G.; Noble, M.; Meyerson, M.; Ladbury, J. E.; Davies, M. A.; Gershenwald, J. E.; Wagner, S. N.; Hoon, D. S. B.; Schadendorf, D.; Lander, E. S.; Gabriel, S. B.; Getz, G.; Garraway, L. A.; Chin, L. Cell 2012, 150, 251.

(2) Ravanat, J. L.; Douki, T.; Cadet, J. J. Photochem. Photobiol. B 2001, $63,88$.

(3) Cadet, J.; Vigny, P. Photochemistry and the nucleic acids, In Bioorganic photochemistry; Morrison, H., Ed.; Wiley-VCH: New York, 1990, 1.

(4) (a) Cadet, J.; Courdavault, S.; Ravanat, J. L.; Douki, T. Pure Appl. Chem. 2005, 77, 947. (b) Cadet, J.; Sage, E.; Douki, T. Mutat. Res. Fund. Mol. Mech. Mut. 2005, 571, 3.

(5) Cadet, J.; Grand, A.; Douki, T. Solar UV radiation-induced DNA bipyrimidine photoproducts: formation and mechanistic insights, In Photoinduced Phenomena in Nucleic Acids II; Barbatti, M.; Borin, A. C.; Ullrich, S., Eds.; Springer International Publishing 2015, 249-275.

(6) (a) Cadet, J.; Wagner, J. R. Cold Spring Harb. Perspect. Biol. 2013, 5, a012559. (b) Cadet, J.; Douki, T.; Gasparutto, D.; Ravanat, J.-L. Mutat. Res. Fund. Mol. Mech. Mut. 2003, 531, 5. (c) Cadet, J.; Douki, T.; Ravanat, J. L. Free Radic. Biol. Med. 2010, 49, 9.

(7) Douki, T.; Cadet, J. Biochemistry 2001, 40, 2495.

(8) Johns, H. E.; Delbruck, M.; Rapaport, S. A. J. Mol. Biol. 1962, 4, 104.

(9) Johns, H. E.; Pearson, M. L.; Helleiner, C. W.; Leblanc, J. C. J. Mol. Biol. 1964, 9, 503.

(10) Mouret, S.; Baudouin, C.; Charveron, M.; Favier, A.; Cadet, J.; Douki, T. Proc. Natl. Acad. Sci. 2006, 103, 13765.

(11) Markovitsi, D. Photochem. Photobiol. 2016, 92, 45.

(12) Premi, S.; Wallisch, S.; Mano, C. M.; Weiner, A. B.; Bacchiocchi, A.; Wakamatsu, K.; Bechara, E. J.; Halaban, R.; Douki, T.; Brash, D. E. Science 2015, 347, 842.

(13) (a) Douki, T.; Sage, E. Photochem. Photobiol. Sci. 2016, 15, 24. (b) Taylor, J. S.; Cohrs, M. P. J. Am. Chem. Soc. 1987, 109, 2834.

(14) Meador, J. A.; Baldwin, A. J.; Pakulski, J. D.; Jeffrey, W. H.; Mitchell, D. L.; Douki, T. Environ. Microbiol. 2014, 16, 1808.

(15) Donnellan, J. E. Jr.; Setlow, R. B. Science 1965, 149, 308.

(16) Smith, K. C.; Yoshikawa, H. Photochem. Photobiol. 1966, 5, 777.

(17) (a) Yang, L.; Li, L. J. Biol. Chem. 2015, 290, 4003. (b) Yang, L.; Li, L. Int. J. Mol. Sci. 2013, 14, 13137.

(18) Desnous, C. l. Guillaume D., Clivio P. 2010, 110, 1213.

(19) (a) Douki, T.; Setlow, B.; Setlow, P. Photochem. Photobiol. Sci. 2005, 4, 591. (b) Douki, T.; Setlow, B.; Setlow, P. Photochem. Photobiol. 2005, 81, 163. (c) Rebeil, R.; Nicholson, W. L. Proc. Natl. Acad. Sci. 2001, 98, 9038.

(20) (a) Chandor, A.; Berteau, O.; Douki, T.; Gasparutto, D.; Sanakis, Y.; Ollagnier-De-Choudens, S.; Atta, M.; Fontecave, M. J. Biol. Chem. 2006, 281, 26922. (b) Buis, J.; Cheek, J.; Kalliri, E.; Broderick, J. J. Biol. Chem. 2006, 281, 25994. (c) Pieck, J.; Hennecke, U.; Pierik, A.; Friedel, M.; Carell, T.J. Biol. Chem. 2006, 281, 36317.

(21) Setlow, P.; Li, L. Photochem. Photobiol. 2015, 91, 1263.

(22) Nicholson, W. L.; Munakata, N.; Horneck, G.; Melosh, H. J.; Setlow, P. Microbiol. Mol. Biol. Rev. 2000, 64, 548.

(23) Varghese, A. J.; Wang, S. Y. Science 1967, 156, 955.

(24) (a) Rebeil, R.; Sun, Y.; Chooback, L.; Pedraza-Reyes, M.; Kinsland, C.; Begley, T. P.; Nicholson, W. L. J. Bacteriol. 1998, 180, 4879. (b) Fajardo-Cavazos, P.; Rebeil, R.; Nicholson, W. Curr. Microbiol. 2005, 51, 331. (c) Chandor-Proust, A.; Berteau, O.; Douki, T.; Gasparutto, D.; Ollagnier-de-Choudens, S.; Fontecave, M.; Atta, M. J. Biol. Chem. 2008, 283, 36361. (d) Chandra, T.; Silver, S. C.; 
Zilinskas, E.; Shepard, E. M.; Broderick, W. E.; Broderick, J. B. J. Am. Chem. Soc. 2009, 131, 2420. (e) Ghose, S.; Hilmer, J. K.; Bothner, B.; Broderick, J. B. FEBS Lett. 2014, 588, 3023. (f) Benjdia, A.; Heil, K.; Barends, T. R. M.; Carell, T.; Schlichting, I. Nucleic Acids Res. 2012, 40, 9308. (g) Benjdia, A.; Heil, K.; Winkler, A.; Carell, T.; Schlichting, I. Chem. Commun. 2014, 50, 14201.

(25) Cheek, J.; Broderick, J. J. Am. Chem. Soc. 2002, 124, 2860.

(26) (a) Yang, L.; Adhikari, J.; Gross, M. L.; Li, L. Photochem. Photobiol. 2017, 93, 331. (b) Yang, L.; Nelson, R. S.; Benjdia, A.; Lin, G.; Telser, J.; Stoll, S.; Schlichting, I.; Li, L. Biochemistry 2013, 52, 3041. (c) Yang, L.; Lin, G.; Nelson, R. S.; Jian, Y.; Telser, J.; Li, L. Biochemistry 2012, 51, 7173. (d) Yang, L.; Lin, G.; Liu, D.; Dria, K. J.; Telser, J.; Li, L. J. Am. Chem. Soc. 2011, 133, 10434.

(27) Landgraf, B. J.; McCarthy, E. L.; Booker, S. J. Annu. Rev. Biochem. 2016, 85, 485.

(28) (a) Fajardo-Cavazos, P.; Salazar, C.; Nicholson, W. L. J. Bacteriol. 1993, 175, 1735. (b) Yang, L.; Li, L. Front. Chem. 2017, 5, 14.

(29) Yang, L.; Jian, Y.; Setlow, P.; Li, L. DNA Repair 2017, 53, 31.

(30) Li, L. Biochim. Biophys. Acta 2012, 1824, 1264.

(31) Lin, G.; Li, L. Angew. Chem. Int. Ed. 2010, 49, 9926.

(32) Lin, G.; Chen, C.-H.; Pink, M.; Pu, J.; Li, L. Chem. Eur. J. 2011, 17, 9658.

(33) Jian, Y.; Li, L. J. Org. Chem. 2013, 78, 3021.

(34) Singh, I.; Jian, Y.; Li, L.; Georgiadis, M. M. Acta Crystallogr. D 2014, 70, 752.

(35) Liu, D.; Li, L. RSC Adv. 2013, 3, 19545.

(36) Liu, D.; Zhou, Y.; Pu, J.; Li, L. Chem. Eur. J. 2012, 18, 7823.

(37) Jian, Y.; Maximowitsch, E.; Liu, D.; Adhikari, S.; Li, L.; Domratcheva, T. Chem. Eur. J. 2017, 23, 7526.

(38) Mantel, C.; Chandor, A.; Gasparutto, D.; Douki, T.; Atta, M.; Fontecave, M.; Bayle, P. A.; Mouesca, J. M.; Bardet, M. J. Am. Chem. Soc. 2008, 130, 16978.

(39) Kim, S. J.; Lester, C.; Begley, T. P. J. Org. Chem. 1995, 60, 6256.

(40) Varghese, A. J. Biochem. Biophys. Res. Commun. 1970, 38, 484.

(41) Douki, T.; Laporte, G.; Cadet, J. Nucleic Acids Res. 2003, 31, 3134.

(42) Ames, D. M.; Lin, G.; Jian, Y.; Cadet, J.; Li, L. J. Org. Chem. 2014, $79,4843$.

(43) (a) Herak, J. N.; McDowell, C. A. J. Magn. Reson. 1974, 16, 434. (b) Herak, J. N. J. Chem. Phys. 1970, 52, 6440. (c) Pruden, B.; Snipes, W.; Gordy, W. Proc. Natl. Acad. Sci. 1965, 53, 917. (d) Shaw, A. A.; Cadet, J. J. Chem. Soc., Perkin Trans. 2 1990, 2063.

(44) Young, D. W.; Tollin, P.; Wilson, H. R. Acta Crystallogr. B 1969 , $25,1423$.

(45) Lee, K. S.; Bumbaca, D.; Kosman, J.; Setlow, P.; Jedrzejas, M. J. Proc. Natl. Acad. Sci. 2008, 105, 2806.

(46) Jian, Y.; Ames, D. M.; Ouyang, H.; Li, L. Org. Lett. 2015, 17, 824.

(47) Peiris, S. Reaction Kinetics, In Static Compression of Energetic Materials; Peiris, S.; Piermarini, G., Eds.; Springer: Berlin Heidelberg, 2008, 203.

(48) Hayes, E. C.; Jian, Y.; Li, L.; Stoll, S. J. Phys. Chem. B 2016, 120, 10923.

(49) (a) Sevilla, M. D. J. Phys. Chem. 1971, 75, 626. (b) Kumar, A.; Sevilla, M. D. Chem. Rev. 2010, 110, 7002.

(50) (a) Matteucci, M. Tetrahedron Lett. 1990, 31, 2385. (b) Gao, X.; Brown, F. K.; Jeffs, P.; Bischofberger, N.; Lin, K. Y.; Pipe, A. J.; Noble, S. A. Biochemistry 1992, 31, 6228. (c) Jones, R. J.; Lin, K. Y.; Milligan, J. F.; Wadwani, S.; Matteucci, M. D. J. Org. Chem. 1993, 58, 2983. (d) Rozners, E.; Strömberg, R. J. Org. Chem. 1997, $62,1846$.

(51) Butenandt, J.; Eker, A. P. M.; Carell, T. Chem. Eur. J. 1998, 4, 642.

(52) Butenandt, J.; Epple, R.; Wallenborn, E.-U.; Eker, A. P. M.; Gramlich, V.; Carell, T. Chem. Eur. J. 2000, 6, 62.
(53) Satou, K.; Komatsu, Y.; Torizawa, T.; Kato, K.; Shimada, I.; Nikaido, O.; Ohtsuka, E. Tetrahedron Lett. 2000, 41, 2175.

(54) Schreier, W. J.; Schrader, T. E.; Koller, F. O.; Gilch, P.; CrespoHernandez, C. E.; Swaminathan, V. N.; Carell, T.; Zinth, W.; Kohler, B. Science 2007, 315, 625.

(55) (a) Slieman, T. A.; Rebeil, R.; Nicholson, W. L. J. Bacteriol. 2000, 182, 6412. (b) Varghese, A. J. Biochemistry 1970, 9, 4781. (c) Varghese, A. J. Photochem. Photobiol. 1971, 13, 357.

(56) (a) Taylor, J.-S.; Brockie, I. R. Nucleic Acids Res. 1988, 16, 5123. (b) Taylor, J. S.; Brockie, I. R.; O'Day, C. L. J. Am. Chem. Soc. 1987, 109, 6735. (c) Ortiz Mayo, J. U.; Thomas, M.; Saintomé, C.; Clivio, P. Tetrahedron 2003, 59, 7377. (d) Friedel, M. G.; Gierlich, J.; Carell, T. Cyclobutane pyrimidine dimers as UV-induced DNA lesions, In The Chemistry of Cyclobutanes; John Wiley \& Sons: Chichester, 2006, 1031. (e) Murata, T.; Iwai, S.; Ohtsuka, E. Nucleic Acids Res. 1990, 18, 7279. (f) Tommasi, S.; Swiderski, P. M.; Tu, Y.; Kaplan, B. E.; Pfeifer, G. P. Biochemistry 1996, 35, 15693. (g) Kosmoski, J. V.; Smerdon, M. J. Biochemistry 1999, 38, 9485. (h) Butenandt, J.; Burgdorf, L. T.; Carell, T. Synthesis 1999, 1085.

(57) Iwai, S.; Shimizu, M.; Kamiya, H.; Ohtsuka, E. J. Am. Chem. Soc. 1996, $118,7642$.

(58) (a) Das, D.; Georgiadis, M. M. Structure 2004, 12, 819. (b) Goodwin, K. D.; Long, E. C.; Georgiadis, M. M. Nucleic Acids Res. 2005, 33, 4106. (c) Cote, M. L.; Pflomm, M.; Georgiadis, M. M. J. Mol. Biol. 2003, 330, 57. (d) Cote, M. L.; Yohannan, S. J.; Georgiadis, M. M. Acta Crystallogr. D 2000, 56, 1120.

(59) Park, H.; Zhang, K.; Ren, Y.; Nadji, S.; Sinha, N.; Taylor, J.-S.; Kang, C. Proc. Natl. Acad. Sci. 2002, 99, 15965.

(60) Jong-Ki Kim, R.; Byong-Seok, C. Eur. J. Biochem. 1995, 228, 849.

(61) Muñoz-Sánchez, J.; Cabrera-Juárez, E. Mutat. Res. Fund. Mol. Mech. Mut. 1991, 251, 21.

(62) (a) Schweitzer, B. A.; Kool, E. T. J. Am. Chem. Soc. 1995, 117, 1863. (b) Guckian, K. M.; Kool, E. T. Angew. Chem. Int. Ed. 1997, 36, 2825.

(63) Kool, E. T.; Sintim, H. O. Chem. Commun. 2006, 3665.

(64) (a) Moran, S.; Ren, R. X.-F.; Kool, E. T. Proc. Natl. Acad. Sci. 1997, 94, 10506. (b) Moran, S.; Ren, R. X. F.; Rumney, S.; Kool, E. T. J. Am. Chem. Soc. 1997, 119, 2056. (c) Kool, E. T. Annu. Rev. Biochem. 2002, 71, 191.

(65) (a) Ostrowski, T.; Maurizot, J.-C.; Adeline, M.-T.; Fourrey, J.-L.; Clivio, P. J. Org. Chem. 2003, 68, 6502. (b) Moriou, C.; Thomas, M.; Adeline, M.-T.; Martin, M.-T.; Chiaroni, A.; Pochet, S.; Fourrey, J.-L.; Favre, A.; Clivio, P. J. Org. Chem. 2007, 72, 43. (c) Desnous, C.; Babu, B. R.; Moriou, C.; Mayo, J. U. O.; Favre, A.; Wengel, J.; Clivio, P. J. Am. Chem. Soc. 2008, 130, 30.

(66) Callis, P. R. Annu. Rev. Phys. Chem. 1983, 34, 329.

(67) Burrows, C. J.; Muller, J. G. Chem. Rev. 1998, 98, 1109.

(68) Lin, G.; Jian, Y.; Dria, K. J.; Long, E. C.; Li, L. J. Am. Chem. Soc. 2014, 136, 12938.

(69) Slieman, T. A.; Nicholson, W. L. Appl. Environ. Microbiol. 2000, 66, 199.

(70) (a) Franklin, W. A.; Lo, K. M.; Haseltine, W. A. J. Biol. Chem. 1982, 257, 13535. (b) Lippke, J. A.; Gordon, L. K.; Brash, D. E.; Haseltine, W. A. Proc. Natl. Acad. Sci. 1981, 78, 3388.

(71) (a) Yoon, J.-H.; Lee, C.-S.; O'Connor, T. R.; Yasui, A.; Pfeifer, G. P. J. Mol. Biol. 2000, 299, 681. (b) Bourre, F.; Renault, G.; Sarasin, A. Nucleic Acids Res. 1987, 15, 8861.

(72) Arichi, N.; Inase, A.; Eto, S.; Mizukoshi, T.; Yamamoto, J.; Iwai, S. Org. Biomol. Chem. 2012, 10, 2318.

(73) Kan, L. S.; Voituriez, L.; Cadet, J. J. Photochem. Photobiol. B 1992, $12,339$. 
(74) Higurashi, M.; Ohtsuki, T.; Inase, A.; Kusumoto, R.; Masutani, C.; Hanaoka, F.; Iwai, S. J. Biol. Chem. 2003, 278, 51968.

(75) Lin, G.; Jian, Y.; Ouyang, H.; Li, L. Org. Lett. 2014, 16, 5076.

(76) Sancar, A. Annu. Rev. Biochem. 1996, 65, 43.

(77) (a) Mori, T.; Matsunaga, T.; Hirose, T.; Nikaido, O. Mutat. Res. 1988, 194, 263. (b) Mori, T.; Nakane, M.; Hattori, T.; Matsunaga, T.; Ihara, M.; Nikaido, O. Photochem. Photobiol. 1991, 54, 225. (c) Strickland, P. T.; Boyle, J. M. Photochem. Photobiol. 1981, 34, 595. (d) Strickland, P. T.; Nikaido, O.; Matsunaga, T.; Boyle, J. M. Photochem. Photobiol. 1992, 55, 723.

(78) (a) Berton, T. R.; Mitchell, D. L.; Guo, R.; Johnson, D. G. Oncogene 2005, 24, 2449. (b) Schul, W.; Jans, J.; Rijksen, Y. M.; Klemann, K. H.; Eker, A. P.; de Wit, J.; Nikaido, O.; Nakajima, S.; Yasui, A.; Hoeijmakers, J. H.; van der Horst, G. T. EMBO J 2002, 21, 4719. (c) Lange, S. S.; Mitchell, D. L.; Vasquez, K. M. Proc. Natl. Acad. Sci. 2008, 105, 10320. (d) Jans, J.; Schul, W.; Sert, Y. G.; Rijksen,
Y.; Rebel, H.; Eker, A. P.; Nakajima, S.; van Steeg, H.; de Gruijl, F. R.; Yasui, A.; Hoeijmakers, J. H.; van der Horst, G. T. Curr. Biol. 2005, 15, 105.

(79) (a) Mitchell, D. L.; Nguyen, T. D.; Cleaver, J. E. J. Biol. Chem. 1990, 265, 5353. (b) Ghosh, R.; Peng, C. H.; Mitchell, D. L. Proc. Natl. Acad. Sci. 1996, 93, 6918. (c) Cleaver, J. E.; Charles, W. C.; McDowell, M. L.; Sadinski, W. J.; Mitchell, D. L. Cancer Res. 1995, 55, 6152. (d) Mitchell, D. L.; Cleaver, J. E.; Lowery, M. P.; Hewitt, R. R. Mutat. Res. 1995, 337, 161. (e) Cheung, K. J. Jr.; Mitchell, D.; Lin, P.; Li, G. Cancer Res. 2001, 61, 4974. (f) Chouinard, N.; Therrien, J. P.; Mitchell, D. L.; Robert, M.; Drouin, R.; Rouabhia, M. Biochem. Cell Biol. 2001, 79, 507. (g) Emmert, S.; Kobayashi, N.; Khan, S. G.; Kraemer, K. H. Proc. Natl. Acad. Sci. 2000, 97, 2151.

(80) Ding, Y.; Fleming, A. M.; Burrows, C. J. J. Am. Chem. Soc. 2017, 139, 2569. 